\title{
RESEÑAS DE CUENTOS APARECIDAS EN LOS DIARIOS ABC (ABC CULTURAL) Y EL PAÍS (BABELIA) 1991-1995 1
}

\author{
Felipe Díaz Pardo
}

Grupo de Investigación del ISLTYNT

\section{CUENTOS EN ESPAÑOL}

\section{España}

\section{A) Obras}

ABAD, Mercedes (1995). Soplando al viento. Barcelona: Tusquets. Reseña: Senabre, Ricardo (1995). ABC Cultural 175, 10-3, 11.

1 Como sistema utilizado en este repertorio, en primer lugar se han introducido los datos bibliográficos del libro en cuestión. A continuación aparece el autor de la reseña, es decir, el crítico, y el año de publicación de dicho texto en el periódico. Al final, se expresa la publicación $-A B C$ Literario, $A B C$ Cultural, El País Libros o Babelia-, señalando el número de la publicación, la fecha y la página donde se ubica. Por último, cabe advertir que, aunque todo lo dicho está en relación con el cuento más actual, también figuran en el listado las reediciones y antologías de autores de cualquier época, encontradas en las fuentes consultadas. 
Aguayo, Mariano (1992). Con mi gente. Palma de Mallorca: José J. de Olañeta. Reseña: N[uria] A[zancot] (1992). ABC Cultural 34, 26-6, 22.

AlfaYA, Javier (1991). El traidor melancólico. Madrid: Alfaguara. Reseña: Senabre, Ricardo (1991). ABC Literario 559, 19-10, IV.

Almodóvar, Pedro (1991). Patty Diphusa y otros textos. Barcelona: Anagrama. Reseña: España, Ramón de (1991). «Españoles famosos. Los meneos de don Camilo y Patty Diphusa». El País Libros 287, 14-4, 2. Álvarez, Blanca (1993). La agonía de los deseos. Madrid: Grupo Libro 88. Reseña: Hernanz, Beatriz (1993). ABC Cultural 108, 26-11, 9.

ÁlvarEZ, Carlos J. (1992). Negra hora menos. Tenerife: Ediciones Tantín y Ayuntamiento de Santa Cruz de Tenerife. Reseña: Cruz, Juan (1992). «El leonés fronterizo». El País (Babelia 29), 2-5, 12.

ÁlvarEZ, Enrique (1990). De perdedores. Caja de Ahorros de León. Reseña: Basanta, Ángel (1991). ABC Literario 537, 18-5, XIII.

AmAT, Nuria (1991). Monstruos. Madrid: Anaya \& Mario Muchnik. Reseña: Basanta, Ángel (1991). ABC Literario 555, 21-9, IV.

Амо, Álvaro del (1992). Niños y bestias. Madrid: Siruela. Reseña: Solé, María (1992). ABC Cultural 43, 28-8, 8.

AMorós, Carmen (1993). ¿Sabes, princesa? Barcelona: Prensa Siete.

Reseña: C[armen] R[odríguez] (1994). ABC Cultural 118, 4-2, 21.

Antoñana, Pablo (1993). La vieja dama. Pamplona: Institución Príncipe de

Viana, Gobierno de Navarra. Reseña: Conte, Rafael (1994). ABC Cultural 114, 7-1, 9.

Aranda, José (1992). Mi ausencia. Barcelona: Montesinos. Reseña: Basanta, Ángel (1992). ABC Cultural, 47, 25-9, 10.

Aranguren, Bárbara (1993). El beso de la rana. Madrid: Libertarias. Reseña: Basanta, Ángel (1993). ABC Cultural 102, 15-10, 9.

ARMIÑÁN, Jaime de (1991). Vidas perras. Madrid: Ediciones Tayo. Reseña: Azancot, Leopoldo (1991). ABC Literario 532, 13-4, IV.

ASENJo SEDANo, José (1993). Historias del exilio. Óptica Almería. Reseña: Senabre, Ricardo (1995). ABC Cultural 193, 14-7, $10^{2}$.

AuB, Max (1991). Crímenes ejemplares. Madrid: Calambur Editorial. Reseñas: Alpuente, Moncho (1992). «La irresistible atracción del crimen. La prosa abrupta de Max Aub, al servicio de las razones de los asesinos». El País (Babelia 17), 8-2, 14; R[afael] C[onte] (1992). ABC Cultural 25, 24-4, 20. AyalA, Francisco (1992). Los usurpadores. Madrid: Cátedra. Reseña: $\mathrm{R}$ [afael] C[onte] (1992). ABC Cultural 32, 12-6, 22.

Ayala, Francisco (1995). Historia de macacos. Madrid: Castalia (Edición de Carolyn Richmond). Reseñas: Goñi, Javier (1995). «De bromas y de

2 Esta reseña aparece incompleta en el periódico, por lo que los datos que faltaban se han obtenido tras consultar el ISBN. 
veras. Nueva edición de "Historias de macacos", de Francisco Ayala». El País (Babelia 198), 29-7, 9; Conte, Rafael (1995). ABC Cultural 198, 18-8, 9.

BAQUero RuiBal, Graciela (1990). Pintura sobre agua. Madrid: Exadra. Reseña: Á[ngel] B[asanta] (1991). ABC Literario 525, 23-2, VI.

BENíTEZ, Francisco (1995). Cuentos ocultos del Sur. Guadalajara: Lípari Ediciones. Reseña: P[ilar] C[astro] (1995). ABC Cultural 209, 3-11, 10.

Benítez ReYes, Felipe (1994). Un mundo peligroso. Madrid: ONCE. Reseña: Basanta, Angel (1994). ABC Cultural 133, 20-5, 10.

BoNILlA, Juan (1994). El que apaga la luz. Valencia: Pre-Textos. Reseñas: García-Posada, Miguel (1994). «Una revelación. Los sorprendentes relatos de un joven narrador». El País (Babelia 148), 20-8, 6; Senabre, Ricardo (1994). ABC Cultural 156, 28-10, 10.

CAMPOS, Jorge (1993). Bombas, astros y otras lejanías. San Sebastián de los Reyes: Universidad Popular. Reseña: Villanueva, Darío (1993). $A B C$ Cultural 71, 12-3-93, 13.

CAMPOS ReINA, Juan (1992). Tango rojo. Barcelona: Edhasa. Reseñas: Cercas, Javier (1992). «Crónicas de la España negra». El País (Babelia, 26), 11-4, 12; Basanta, Ángel (1992). ABC Cultural 37, 17-7, 8.

CARrión, Ignacio (1992). Klaus ha vuelto. Madrid: Mondadori. Reseñas: R[icardo] S[enabre] (1992). ABC Cultural 12, 24-1, 21; Cruz, Juan (1992). «Relatos frescos y existencialistas. Ignacio Carrión, el sutil equilibrio entre la literatura y el periodismo». El País (Babelia 22), 14-3, 15. CASTRO, Antón (1995). El testamento de amor de Patricio Julve. Barcelona:

Destino. Reseña: M. G. T. (1995). «Imaginativos y sorprendentes relatos». El País (Babelia 212), 11-11, 12.

Cela, Camilo José (1991). Cachondeos, escarceos y otros meneos. Madrid: Temas de Hoy. Reseña: España, Ramón de (1991). «Españoles famosos. Los meneos de don Camilo y Patty Diphusa». El País Libros 287, 14-4, 2. Cela, Camilo José (1991). Gavilla de fábulas sin amor. Madrid: EspasaCalpe, colección Acanto. Reseña: S/A (1991). ABC Literario 555, 21-9, XIV.

Cela, Camilo José (1992). Esas nubes que pasan. Madrid: Espasa-Calpe. Reseña: R[afael] C[onte] (1992). ABC Cultural 55, 20-11, 22.

Cela, Camilo José (1994). La dama pájara. Madrid: Espasa Calpe. Reseña: Marco, Joaquín (1994). ABC Cultural 156, 28-10, 7.

Cerezales, Agustín (1991). Escaleras en el limbo. Barcelona: Editorial Lumen. Reseña: Marco, Joaquín (1991). ABC Literario 533, 20-4, III. Colinas, Antonio (1994). Dias en Petavonium. Barcelona: Tusquets.

Reseña: Conte, Rafael (1994). ABC Cultural 149, 9-9, 10.

CONDE, Juan Luis (1990). La ascensión del hoyo. Madrid: Libertarias. Reseña: I[gnacio] Echevarría (1991). El País Libros 278, 10-2, 11. 
Delgado, Javier (1992). Memoria vencida. Barcelona: Lumen. Reseñas: Marín, Juan (1992). «Recordar para vivir. Javier Delgado y la vuelta al realismo». El País (Babelia 56), 7-11, 13; Senabre, Ricardo (1992). ABC Cultural 55, 20-11, 10.

DeliBes, Miguel (1994). Los niños. Barcelona: Planeta. Reseña: I. S. C. (1994). ABC Cultural 163, 16-12, 25.

DesmonTs, Antonio J. (1990). Los tranvías de Praga. Barcelona: Península (1991). Reseña: Basanta, Ángel (1991). ABC Literario 518, 5-1, V.

Díez, Luis Mateo (1993). Los males menores. Madrid: Alfaguara. Reseñas: García-Posada, Miguel (1993). «Entre la continuidad y la renovación. Nuevas visiones en el último libro de cuentos de Luis Mateo Díez». El País (Babelia 104), 9-10, 13; Conte, Rafael (1993). ABC Cultural 108, 26-11, 10.

Escudero, Alberto (1991). El sofá tapizado de flores. Madrid: Libertarias/Prodhufi. Reseña: Basanta, Ángel (1991). ABC Cultural 1, 811,8 .

ESCUDERO, Alberto (1994). Un error de bulto. Pamplona: Hierbaola. Reseña: Basanta, Ángel (1994). ABC Cultural 120, 18-2, 10.

EsPINA, Antonio (1992). Pájaro pinto. Madrid: Libertarias/Prodhufi. Reseña: $\mathrm{R}$ [afael] C[onte] (1993). ABC Cultural 68, 19-2, 20.

EZQUERRA, Iñaki (1992). La caída del caserio Usher. Madrid: Libertarias.

Reseña: Basanta, Ángel (1992). ABC Cultural 31, 5-6, 9.

FERNÁNDEZ, Manuel Francisco (1992). El hacerse es deshacerse. Granada: Impredisur. Reseña: S. C. (1993). ABC Cultural 68, 19-2, 20.

FERNÁNDEZ Cubas, Cristina (1994). Con Agatha en Estambul. Barcelona: Tusquets. Reseñas: Ayala-Dip, J. Ernesto (1994). «El deseo de seducir. Cinco relatos cortos de Cristina Fernández Cubas». El País (Babelia 135, 21-5, 10); Senabre, Ricardo (1994). ABC Cultural 135, 3-6, 9.

FERnÁndeZ Molina, Antonio (1991). En Cejunta y Gamud. Madrid: Prensa y Ediciones Iberoamericanas. Reseña: Senabre, Ricardo (1991). $A B C$ Literario 560, 26-10, VI.

Fernández Molina, Antonio (1992). Sombras chinescas. Madrid: Libertarias. Reseña: Á[ngel] B[asanta] (1992). ABC Cultural 50, 16-10, 12.

FERRER-VIDAL, Jorge (1990). El cálido verano del 44. Madrid: Ediciones Iberoamericanas. Reseña: Basanta, Ángel (1991). ABC Literario 522, 2 2, VI.

FERrer-VIDAL, Jorge (1994). Los iluminados. Barcelona: Anthropos. Reseña: Basanta, Ángel (1994). ABC Cultural 165, 30-12, 10.

GuACHE, Ángel (1994). Sopa nocturna. Valencia: Pre-Textos. Reseña: Senabre, Ricardo (1994). ABC Cultural 151, 23-9, 11.

Gallego, Vicente (1994). Cuentos de un escritor sin éxito. Valencia: PreTextos. Reseña: Senabre, Ricardo (1994). ABC Cultural 137, 17-6, 8. 
GÁNDARA, Alejandro (1990). El final del cielo. Madrid: Siruela. Reseña: Méndez, José (1991). ABC Literario 524, 16-2, V.

GARBI, Teresa (1993). La sombra y el pozo. Madrid: Libertarias. Reseña: Senabre, Ricardo (1993). ABC Cultural 109, 3-12, 10.

García Calvo, Agustín: ¿Qué coños? Cinco cuentos y una charla. Zamora: Editorial Lucina. Reseña: Murillo, Enrique (1991). «Pornógrafo excelente. Nueve cuentos de Agustín García Calvo». El País Libros 274, 131-3.

García Hortelano, Juan (1992). Cuentos completos. Madrid: Alianza, 2 vols. Reseña: Conte, Rafael (1993). ABC Cultural 63, 15-1, 7.

GARCÍA SÁNCHEZ, Javier (1991). Crítica de la razón impura. Barcelona, Edhasa. Reseña: R[afael] C[onte] (1991). ABC Cultural 8, 27-12, 20.

García Serrano, Rafael (1995). Los toros de Iberia. Bilbao: Ediciones Laga. Reseña: R[afael] C[onte] (1995). ABC Cultural 201, 8-9, 23.

Giralt TORRENTE, Marcos (1995). Entiéndame. Barcelona: Anagrama. Reseñas: Santos, Care (1995). ABC Cultural 188, 9-6, 10; Echevarría, Ignacio (1995). «Siete relatos. Marcos Giralt Torrente, un nuevo y solvente narrador». El País (Babelia 196), 15-7, 9.

GRANDE, Félix (1995). Decepción. Madrid: El País/Aguilar. Reseña: Senabre, Ricardo (1995). ABC Cultural 180, 14-4, 11.

GranEll, Eugenio (1993). Federica no era tonta. Alcalá de Henares: Fugaz/Ediciones. Reseña: C. R. (1993). ABC Cultural 73, 26-3, 21.

Guerra Garrido, Raúl (1991). Micrófono oculto. Madrid: Mondadori. Reseña: Basanta, Ángel (1991). ABC Literario 553, 7-9, V.

IRISARRI, Ángeles de (1995). Siete cuentos históricos y siete que no lo son. Zaragoza: Zócalo. Reseña: J. M. (1995). «La letra pequeña de la Historia». El País (Babelia 216), 9-12, 9.

IZQUIERDO, José María (1995). Recuerdos de un cirujano. Oviedo: Ediciones

Nobel. Reseña: Rodríguez Santos, Carmen (1995). ABC Cultural 206, 13-10, 10.

JIMÉNEZ LoZANO, José (1991). Los grandes relatos. Barcelona: Anthropos. Reseña: Senabre, Ricardo (1991). ABC Literario 545, 13-7, V.

JiménEZ LozANo, José (1993). El cogedor de acianos. Barcelona: Anhropos. Reseña: Mate, Reyes (1994). «El lenguaje puro del relato. José Jiménez Lozano reivindica los mundos olvidados». El País (Babelia 122), 19-2, 11.

LeÓN, María Teresa (1992). La bella del mal amor. Madrid: Cairel. Reseña: T[rinidad] L[eón] S[otelo] (1993). ABC Cultural 65, 29-1, 23.

Lezcano, María Teresa (1991). Mujeres en la ciudad. Málaga: Colección Aldea. Reseña: Basanta, Ángel (1991). ABC Cultural 4, 29-11, 8.

LORIGA, Ray (1994). Días extraños. Madrid: Ediciones Detursa. Reseña: $\mathrm{R}$ [afael] C[onte] (1994). ABC Cultural 137, 17-6, 21. 
LlamaZARES, Julio (1995). En mitad de ninguna parte. Madrid: Ollero \& Ramos. Reseñas: R[icardo] S[enabre] (1995). ABC Cultural 208, 27-10, 10; Goñi, Javier (1995). «El especial paisaje de Llamazares. Humor, ironía, sarcasmo y tozudez en los relatos que el escritor leonés ha reunido en un libro». El País (Babelia 211), 4-11, 11.

Llop, José Carlos (1991). Pasaporte diplomático. Barcelona: Muchnik. Reseñas: Senabre, Ricardo (1991). ABC Literario 549, 10-8, V; Echevarría, Ignacio (1991). «Buenas maneras. Cuatro relatos de intriga y misterio de J. C. Llop». El País Libros 307, 1-9, 2.

MADRID, Juan (1995). Crónicas del Madrid oscuro. Madrid: El País/Aguilar. Reseñas: Basanta, Ángel (1995). ABC Cultural 168, 20-1, 9; Valenzuela, Javier (1995). El País (Babelia 176), 4-3, 11.

MAGRINYÁ, Luis (1993). Los aéreos. Madrid: Debate. Reseña: Echevarría, Ignacio (1993). «Productos de escritorio. Los sorprendentes logros narrativos de Luis Magrinyá». El País (Babelia 106), 23-10, 13.

MAGRINYÁ, Luis (1995). Belinda y el monstruo. Madrid: Debate. Reseña: Echevarría, Ignacio (1995). «Amores particulares. El rigor y la lucidez de una inusual apuesta narrativa». El País (Babelia 185), 6-5, 12.

MAllorquí, César (1995). El círculo de Jericó. Barcelona: Ediciones B. Reseña: Cuenca, Luis Alberto de (1995). ABC Cultural 203, 22-9, 10. MARQUÉS DE TAMARÓN (Santiago de Mora-Figueroa) (1990). Trampantojos. Madrid: Mondadori. Reseña: Schwartz, Fernando (1991). «Un poco de ironía». El País Libros 288, 21-4, 2.

MARTÍNEZ MENCHÉN, Antonio (1993). Una infancia perdida. Madrid: Mondadori. Reseña: Senabre, Ricardo (1993). ABC Cultural 74, 2-4, 10.

MARTíneZ DE MiNGo, Luis (1995). Bestiario del corazón. Madrid: Grupo Libro 88. Reseña: Basanta, Ángel (1995). ABC Cultural 181, 21-4, 10. MARTíNEZ DE PISÓN, Ignacio (1994). El fin de los buenos tiempos. Barcelona: Anagrama. Reseñas: Echevarría, Ignacio (1994). «La pulsión parricida. La definitiva madurez de Ignacio Martínez de Pisón». El País (Babelia 119), 29-1, 11; Senabre, Ricardo (1994). ABC Cultural 118, 4-2, 9.

MatuTe, Ana María (1992). Los niños tontos. Barcelona: Destino. Reseña: $\mathrm{R}$ [afael] C[onte] (1992). ABC Cultural 57, 4-12, 22.

MAYRATA, Ramón (1991). Si me escuchas esta noche. Madrid: Mondadori. Reseña: Basanta, Ángel (1992). ABC Cultural 11, 17-1, 8.

MENDICUTTI, Eduardo (1995). Fuego de marzo. Barcelona: Tusquets. Reseñas: Basanta, Ángel (1995). ABC Cultural 214, 8-12, 20; Giralt Torrent, Marcos (1995). «Visiones de la infancia. Eduardo Mendicutti reúne en un volumen nueve relatos escritos a lo largo de los últimos veinte años». $E l$ País (Babelia 216), 9-12, 10.

Merino, José María (1994). Cuentos del Barrio del Refugio. Madrid: Alfaguara. Reseñas: García-Posada, Miguel (1994). «Los poderes de la literatura. 
Nueva incursión de José María Merino en la narrativa fantástica». El País (Babelia 138), 11-6, 12; Conte, Rafael (1994). ABC Cultural 137, 17-6, 11. MILLÁN, José Antonio (1990). La memoria (y otras extremidades). Barcelona: Sirmio. Reseña: Echevarría, Ignacio (1991). «El ingenio y la malicia». El País Libros 286, 7-4, 2.

MillÁs, Juan José (1992). Primavera de luto. Barcelona: Destino. Reseña: Ayala-Dip, J. Ernesto (1992). «Las tinieblas de la realidad. Juan José Millás reúne en un volumen 23 cuentos aparecidos en diversas publicaciones». El País (Babelia 28), 25-4, 14.

Millás, Juan José (1994). Ella imagina. Madrid: Alfaguara. Reseñas: AyalaDip, J. Ernesto (1994). «La más pura ficción». El País (Babelia 128), 313, 9; Senabre, Ricardo (1994). ABC Cultural 130, 29-4, 10.

Mingote, Antonio (1993). De muerte natural. Madrid: Espasa-Calpe. Reseña: Lázaro Carreter, Fernando (1993). ABC Cultural 71, 12-3, 9.

MiÑANA, Juan (1992). Última sopa de rabo de la tertulia España. Barcelona: Edhasa. Reseñas: I[gnacio] E[chevarría] (1992). «El toro por los cuernos. Juan Miñana explora con sarcasmo algunos aspectos de la tradición española». El País (Babelia 33), 30-5, 13; Basanta, Ángel (1992). ABC Cultural 48, 2-10, 10.

MiRó, Gabriel (1991). Años y leguas. Valencia: Ediciones Aitana. Reseña: J. R. (1992). ABC Cultural 14, 7-2, 20.

MoIX, Ana María (1995). Ese chico pelirrojo a quien veo cada día. Barcelona: Lumen. Reseña: Castro, Pilar (1995). ABC Cultural 193, 14-7, 9. MoRENo, José Luis (1992). Danzón canalla. Madrid: Grupo Libro 88. Reseña: Basanta, Ángel (1992). ABC Cultural 57, 4-12, 10.

MúGICA, Daniel (1990). Mar calamidad. Madrid: Mondadori. Reseña: Guzmán, Almudena (1991). ABC Literario 523, 9-2, V.

MuÑoz Molina, Antonio (1993). Nada del otro mundo. Madrid: EspasaCalpe. Reseñas: Goñi, Javier (1993). «Muñoz Molina, en pequeño formato». El País (Babelia 111, 27-11, 11); Marco, Joaquín (1993). ABC Cultural 110, 10-12, 12.

Moreno Villa, José (1991). Patrañas. Madrid: Aguilar. Reseña: J. C. Rosales (1991). El País Libros 296, 16-6, 11.

Navales, Ana María (1991). Cuentos de Bloomsbury. Madrid: Edhasa. Reseñas: S/A ${ }^{3}$ (1991). El País (Babelia 1), 19-10, 20; Basanta, Ángel (1991). $A B C$ Literario 558, 13-10, IV.

NAvales, Ana María (1992). Zacarías, rey. Huelva: Diputación Provincial. Reseña: Senabre, Ricardo (1992). ABC Cultural 59, 18-12, 10.

NiETo MANJón, Luis (1993). Historias de un alguacilillo. Madrid: Ed. Fernando Plaza del Amo. Reseña: Basanta, Ángel (1993). ABC Cultural 96, 3-9, 9.

\footnotetext{
3 Se desconoce el autor de la reseña. $\mathrm{S} / \mathrm{A}=\sin$ autor.
} 
ONAINDÍA, Mario (1991). Cuentos nocturnos. Barcelona: Editorial Edhasa. Reseña: Senabre, Ricardo (1991). ABC Literario 537, 18-5, XIII.

ORBEGOzo, María Jesús (1991). Sueño sin trenzas. Madrid: La Palma. Reseña: Arias, Juan (1992). «Las lágrimas de la mujer. María Orbegozo, un viaje singular por el universo femenino». El Pais (Babelia 17), 8-2, 14.

ORDÓÑEZ, Marcos (1991). La esencia del guaguancó. Barcelona: Versal. Reseña: Basanta, Ángel (1991). ABC Literario 528, 16-3, II.

ORTEGA SPOTTORNo, José (1990). Relatos en espiral. Madrid: Espasa Calpe. Reseña: Á[ngel] B[asanta] (1991). ABC Literario 526, 2-3: VII.

ORTEGA SPOTTORNo, José (1995). Los amores de cinco minutos. Madrid: El País/Aguilar. Reseña: Castro, Pilar (1995). ABC Cultural 217, 29-12, 11. Peraile, Meliano (1993). Materia viva. Madrid: Libertarias. Reseña: Basanta, Ángel (1993). ABC Cultural 93, 13-8, 10.

Pereira, Antonio (1991). Picassos en el desván. Madrid: Mondadori. Reseña: Gullón, Ricardo (1991). ABC Literario 525, 23-2, III.

PereIRA, Antonio (1994). Las ciudades de Poniente. Madrid: Anaya \& M. Muchnik. Reseñas: Senabre, Ricardo (1994). ABC Cultural 155, 21-10, 9; Santos, Dámaso (1995). «El depurado arte de narrar. Ironía y ternura en los cuentos de Antonio Pereira». El País (Babelia 171), 28-1, 11.

PÉrez REverTe, Arturo (1993). La sombra del águila (un relato). Madrid: Alfaguara. Reseña: Vázquez Rial, Horacio (1994). «Un error de Napoléon. Pérez-Reverte, corresponsal en la campaña de Rusia». El País (Babelia 118), 22-1, 11.

Prada, Juan Manuel de (1995). Coños. Madrid: Valdemar. Reseña: F[ernando] R. L[afuente] (1995). ABC Cultural 190, 23-6, 21.

PRADA, Juan Manuel de (1995). El silencio del patinador. Madrid: Valdemar. Reseñas: García-Posada, Miguel (1995). «La pasión de la literatura. Juan Manuel de Prada confirma sus cualidades en un excelente libro de relatos llenos de imaginación y estilo». El País (Babelia 214), 25-11, 10; Senabre, Ricardo (1995). ABC Cultural 213, 1-12, 11.

PuÉRTOLAS, Soledad (1993). La corriente del golfo. Barcelona: Anagrama. Reseñas: Echevarría, Ignacio (1993). «La tristeza redimida. El talento narrativo de Soledad Puértolas, al servicio del relato». El País (Babelia 101), 18-9, 14-15; Senabre, Ricardo (1993). ABC Cultural 102, 15-10, 9. RIERA, Carme (1991). Contra el amor en compañía y otros relatos. Barcelona: Destino. Reseñas: Bou, Enric (1991). «Carme Riera: cuentos y experimentos. Las dos voces de una narradora con lectores». El País Libros 302, 28-7, 2; Basanta, Ángel (1991). ABC Literario 549, 10-8, VI. Ríos, Julián (1993). Sombreros para Alicia. Barcelona: Muchnik. Reseña: Basanta, Ángel (1994). ABC Cultural 116, 21-1, 10.

RossetTI, Ana (1991). Alevosías. Barcelona: Tusquets. Reseña: Ayala Dip, J. Ernesto (1991). «Escribir el deseo». El País Libros, 290, 5-5, 3. 
SÁENZ-ANGulo, Julia (1995). Amigas de Judit. Madrid: Libertarias-Prodhufi.

Reseña: Rodríguez Santos, Carmen (1995). ABC Cultural 183, 5-5, 10.

SAlvador, Gregorio (1994). Casualidades. Madrid: Espasa Calpe. Reseña:

Senabre, Ricardo (1994). ABC Cultural 160, 25-11, 10.

SAMPEDRo, José Luis (1992). Mar al fondo. Barcelona: Destino. Reseñas:

Conte, Rafael (1992). ABC Cultural 56, 27-11, 6; García-Posada, Miguel

(1993). «Los buenos sentimientos. Los cuentos de aprendizaje de Sampedro». El País (Babelia 67), 23-1, 13.

SAMPEDRo, José Luis (1993). Mientras la tierra gira. Barcelona: Destino.

Reseña: Lázaro Carreter, Fernando (1993). ABC Cultural 82, 28-5, 7.

SÁNCHEZ FERLOSIO, Rafael (1993). Vendrán más años malos y nos harán más ciegos. Barcelona: Destino. Reseña: Marco, Joaquín (1993). ABC Cultural 109, 3-12, 10.

SANTOS, Care (1995). Cuentos cítricos. Madrid: Libertarias. Reseña: Castro, Pilar (1995). ABC Cultural 214, 8-12, 20.

SEgovia, Tomás (1991). Personajes mirando a una nube. Madrid: Mondadori. Reseña: Marco, Joaquín (1991). ABC Literario 527, 9-3, VI.

Serrano, Felipe (1993). Cuentos de la fascinación. Madrid:

Libertarias/Prodhufi. Reseña: Basanta, Ángel (1993). ABC Cultural 71, $12-3,10$.

Soto, Vicente (1991). Pasos de nadie. Barcelona: Editorial Edhasa. Reseña: Marco, Joaquín (1991). ABC Literario 532, 13-4, V.

SuÁrEZ, Gonzalo (1994). El asesino triste. Madrid: Alfaguara. Reseñas: Mora, Rosa (1994). «Un escritor de culto. Gonzalo Suárez publica "El asesino triste"». El País (Babelia 130), 16-4, 13; Conte, Rafael (1994). ABC Cultural 131, 6-5,11.

TALENS, Manuel (1994). Venganzas. Barcelona: Tusquets. Reseñas: Villanueva, Darío (1994). ABC Cultural 156, 28-10, 9; Obiol, María José (1994). «Relatos de un ucronista. Manuel Talens o la literatura como desquite». El País (Babelia 161, 19-11, 10).

Tzzón, Eloy (1992). Velocidad de los jardines. Barcelona: Anagrama. Resenas: Conte, Rafael (1992). ABC Cultural 51, 23-10, 11; Echevarría, Ignacio (1992). «Una escritura amenazada. La intensidad lírica de los relatos de Eloy Tizón». El País (Babelia 59), 28-11, 11.

TOMEO, Javier (1993). Zoopatías y zoofilias. Madrid: Mondadori. Reseñas: Senabre, Ricardo (1993). ABC Cultural 84, 11-6, 10; Peña, Luis de la (1993). «El zoológico humano. Los cuentos breves de Javier Tomeo». El País (Babelia 92), 17-7, 11.

Tomeo, Javier (1994). El nuevo bestiario. Barcelona: Planeta. Reseña: Basanta, Ángel (1994). ABC Cultural 159, 18-11, 9.

UgARTE, Pedro (1990). Los traficantes de palabras. Barcelona: Mursia. Reseña: Á[ngel] B[asanta] (1991). ABC Literario 527, 9-3, V. 
UgARTE, Pedro (1992). Noticia de tierras improbables. Pamplona: Hierbaola. Reseña: Basanta, Ángel (1992). ABC Cultural 59, 18-11, 8.

Valle-InClán, Ramón María del (1992). Femeninas. Epitalamio. Madrid: Cátedra. Reseña: M[auro] A[rmiño] (1992). ABC Cultural 61, 31-12, 27.

VÁZQUEZ MonTALBÁN, Manuel (1994). El hermano pequeño. Barcelona: Planeta. Reseña: Senabre, Ricardo (1994). $A B C$ Cultural 128, 15-4, 41.

VICANDI, Ana (1991). La incompostura en la mesa. Madrid: Torre Manrique Publicaciones. Reseña: Basanta, Ángel (1992). ABC Cultural 15, 14-2, 8.

VILA-MATAS, Enrique (1991). Suicidios ejemplares. Barcelona: Anagrama. Reseñas: Echevarría, Ignacio (1991). «Ignorar la vida. La lenta maduración de Enrique Vila-Matas». El País Libros 284, 24-3, 4; Basanta, Ángel (1991). ABC Literario 536, 11-5, V.

VIla-Matas, Enrique (1993). Hijos sin hijos. Barcelona: Anagrama. Reseñas: Echevarría, Ignacio (1993). «Sombras checas. La extraña belleza de los relatos de Vila-Matas». El País (Babelia 71), 20-2, 11; Ángel Basanta (1993). ABC Cultural 85, 18-6, 10.

VILlena, Luis Antonio de (1994). El tártaro de las estrellas. Valencia: PreTextos. Reseña: Hernanz, Beatriz (1994). ABC Cultural 131, 6-5, 12.

ZENTNER, Jorge (1994). Mertov. Madrid: Anaya \& Mario Muchnik. Reseña: Castro, Pilar (1994). ABC Cultural 128, 15-4, 12.

ZúNílGA, Juan Eduardo (1992). Misterios de las noches y los días. Madrid: Alfaguara. Reseñas: Conte, Rafael (1992). ABC Cultural 25, 24-4, 9; García-Posada; Miguel (1992). «Sombras y enigmas. Zúñiga sorprende con unos relatos de corte fantástico». El País (Babelia 29), 2-5, 12.

\section{B) Antologías}

AlDECOA, Ignacio (1995). Cuentos completos (1949-1969). Madrid: Alfaguara. Reseñas: García-Posada, Miguel (1995). «El narrador de historias. Nueva e íntegra edición de los cuentos de Ignacio Aldecoa». El País (Babelia 178), 18-3, 10; Conte, Rafael (1995). ABC Cultural 180, 14-4, 7. ANónimo (1991). Cuentos andaluces. Palma de Mallorca: Olañeta (Prólogo y selección de C. Bravo Villasante). Reseña: S/A (1991). ABC Literario 518, 5-1, XIV.

ANÓNIMO (1994). Cuentos y tradiciones japoneses. Madrid: Hiperión (Recopilación de Luis Caeiro), 2 volúmenes. Reseña: R. Lafuente, Fernando (1994). ABC Cultural 153, 7-10, 124.

4 El ISBN no consigna la lengua de la que se traduce esta obra.. 
Aub, Max (1995). Enero sin nombre. Barcelona: Alba Editorial. Reseña: Conte, Rafael (1995). ABC Cultural 170, 3-2, 9.

Aub, Max (1995). Escribir lo que imagino. Barcelona: Alba Editorial. Reseña: Conte, Rafael (1995). ABC Cultural, 179, 3-2, 9.

Ayala, Francisco (1993). Relatos granadinos. Ayuntamiento de Granada (Ed. J. Paredes Núñez). Reseña: M[iguel] G[arcía]-P[osada] (1991). $A B C$ Literario 520, 19-1, IV.

Ayala, Francisco (1993). Narrativa completa. Madrid: Alianza. Reseña: Conte, Rafael. ABC Cultural, 80, 14-5, 9.

Azorín [José Martínez Ruiz] (1992). Fabia Linde y otros cuentos. Yecla: Ateneo Literario (Edición de M. Martínez del Portal). Reseña: Conte, Rafael (1992). ABC Cultural 55, 20-11, 9.

ChaVes Nogales, Manuel (1994). Obra narrativa completa. Diputación de Sevilla, 2 vols. Reseña: Senabre, Ricardo (1994). ABC Cultural 142, $22-$ 7,11 .

Clarín [Leopoldo Alas] (1991). «Vario»... y Varia. Madrid: Orígenes (Edición de C. Richmond). Reseña: R[afael] C[onte] (1992). ABC Cultural 16, 21-2, 21.

CunqueIro, Álvaro (1991). La historia del caballero Rafael. Barcelona: Edhasa. Reseña: S/A (1991). ABC Literario 559, 19-10, IV.

Fralle, Medardo (1991). Cuentos completos. Madrid: Alianza Editorial. Reseña: Conte, Rafael (1991). ABC Cultural 6, 13-12, 35.

GonZÁlez RuANo, César (1994). Dos cuentos italianos. Madrid: Fundación Mapfre-Vida. Reseña: Conte, Rafael (1994). ABC Cultural 144, 5-8, 7. Jiménez Lozano, José (1993). Objetos perdidos. Valladolid: Ámbito. Reseña: Lázaro Carreter, Fernando (1993). ABC Cultural 99, 24-9, 7.

MARTín GAITE, Carmen (1994). Cuentos completos y un monólogo. Barcelona: Anagrama. Reseña: R[afael] C[onte] (1994). ABC Cultural 130, 29-4, 19. MASIP, Paulino (1993). El gafe. Logroño: Gobierno de la Rioja. Reseña: $\mathrm{R}$ [afael] C[onte] (1993). ABC Cultural 83, 4-6, 23.

Miró, Gabriel (1991). Huerto de cruces. Barcelona: Edhasa (Selección de F. Márquez). Reseña: S/A (1991). ABC Literario 557, 5-10, XV.

Pereda, José María (1992). El fin de una raza. Barcelona: Edhasa. Reseña: $\mathrm{R}$ [afael] C[onte] (1992). ABC Cultural 19, 13-3, 14.

Pérez ReverTe, Arturo (1995). Los héroes cansados. Madrid: Espasa Calpe. Reseña: R[afael] C[onte] (1995). ABC Cultural 187, 2-6, 22.

PÉreZ REVERTE, Arturo (1995). Obra breve-1. Madrid: Alfaguara. Reseñas: I. S. C. (1995). ABC Cultural 198, 18-8, 19; Mora, Rosa (1995). «!Maldita gloria! Pérez Reverte reúne en un libro tres relatos y su primera novela». El País (Babelia 200), 19-8, 7.

VELÁZQUEZ RIERA, Roberto (1990). Moriré esta primavera. Madrid: Bitácora. Reseña: Basanta, Ángel (1991). ABC Literario 523, 9-2, V. 
Verdaguer, Mario (1993). Obra inédita. Palma de Mallorca: Revista Bitzoc. Reseña: Conte, Rafael (1993). ABC Cultural 78, 30-4, 9.

VV.AA. (1990). El fin del milenio. Barcelona: Planeta. Reseña: J. E[ernesto] Ayala-Dip (1991). El País Libros 273, 6-1, 11.

VV.AA. (1990). Los pecados capitales. Madrid: Grijalbo/Mondadori. Reseñas: Méndez, José (1991). ABC Literario 518, 5-1, VI; Echevarría, Ignacio (1991). «Relatos veniales. 14 autores españoles cuentan sus pecados capitales». El País Libros 274, 13-1, 2.

VV.AA. (1990). Relatos eróticos. Madrid: Castalia-Instituto de la Mujer. Reseña: [Ignacio] Echevarría (1991). El País Libros 281, 3-3, 11.

VV. AA. (1991). Negro como la noche. Gijón/Madrid: Júcar (Selección de Manuel Quinto). Reseña: Navarro, Justo (1991). ABC Literario 556, 28-9, VI. VV.AA. (1991). Breves, deseables y perversos. Madrid: Editorial Horas y Horas. Reseña: León-Sotelo, Trinidad de (1991). ABC Cultural 1, 811,10 .

VV.AA. (1991). Todo va de cuentos. Madrid: Horas y Horas. Reseña: T[rinidad] L[eón]-S[otelo] (1992). ABC Cultural 14, 7-2, 20.

VV.AA. (1992). Antología española de literatura fantástica. Madrid: Valdemar (Selección de A. Martínez). Reseña: Senabre, Ricardo (1992). ABC Cultural 36, 10-7, 11.

VV.AA. (1993). Últimos narradores. Pamplona: Hierbaola (Selección de J. L. González y P. de Miguel). Reseña: Conte, Rafael (1993). ABC Cultural 93, 13-8, 7 .

VV.AA. (1993). Retablo y geografía de cuentos canarios. Canarias: Gobierno de Canarias (Selección de Sebastián de la Nuez y Flora Lilia Barrera). Reseña: R[icardo] S[enabre] (1993). ABC Cultural 88, 9-7, 10.

VV.AA. (1993). Cuento español contemporáneo. Madrid: Cátedra (Edición de Ángeles Encinar y Anthony Percival). Reseña: R[afael] C[onte] (1993). ABC Cultural 104, 29-10, 20.

VV.AA. (1993). Son cuentos. Madrid: Espasa-Calpe (Edición de Fernando Valls). Reseña: R[afael] C[onte] (1993). ABC Cultural 108, 26-11, 22. VV.AA. (1993). Antología de la novela corta erótica española de entreguerras. Madrid: Taurus (Edición de Lily Litvak). Reseña: Pereda, Rosa (1993). «Los herederos de la literatura libertina. Una antología recoge 18 relatos eróticos de entreguerras». El País (Babelia 113), 11-12, 12.

VV.AA. (1994). Cuentos modernistas. Madrid: Ed. Popular/Unesco. Reseña: T[rinidad] L[ópez] S[otelo] (1994. ABC Cultural 139, 1-7, 225.

VV.AA. (1994). Cuentos bíblicos. Barcelona: Montesinos. Reseña: Senabre, Ricardo (1994). ABC Cultural 149, 9-9, 11.

5 Este volumen aparece citado también en el apartado «antologías» del grupo de literatura hispanoamericana, puesto que en él se incluyen autores tanto españoles como de Hispanomérica. 
VV.AA. (1994). Antología del cuento español, 1900-1939. Madrid: Castalia (Edición de José M. ${ }^{a}$ Martínez Cachero). Reseña: R[afael] C[onte] (1994). ABC Cultural 151, 23-9, 23.

VV.AA. (1994). Relatos urbanos. Madrid: Alfaguara. Reseñas: J[avier] G[oñi] (1994). El País (Babelia 159), 5-11: 13; Castro, Pilar (1995). ABC Cultural 177, 24-3, 10.

VV.AA. (1994). Cuentos de la isla del tesoro. Madrid: Alfaguara. Reseñas: J[avier] G[oñi] (1994). El País (Babelia 159), 5-11: 13; Castro, Pilar (1995). ABC Cultural 177, 24-3, 10.

VV.AA. (1994). La primera pelea. Madrid: Alfaguara. Reseña: Millán, José Antonio (1994). «Ellos escriben». El País (Babelia 131), 23-4, 9.

VV.AA. (1995). Otras voces, 2. Madrid: Alfaguara. Reseña: Santos, Care (1995). ABC Cultural 203, 22-9, 10.

VV.AA. (1995). De la Luna a Mecanópolis. Antología de la ciencia-ficción española (1832-1913). Barcelona: Sirmio (Selección e introducción de Nil Santiáñez-Tió). Reseña: Antón, Jacinto (1995). «iTiembla Julio Verne! Una antología reivindica el papel pionero de la ciencia-ficción española». El País (Babelia 209), 21-10, 11.

VV.AA. (1995). Cuentos de fútbol. Madrid: Alfaguara (Selección de Jorge Valdano). Reseña: Goñi, Javier (1995). «La seducción de la esfera. Una recopilación de relatos en los que el fútbol es dueño y señor del texto. Desde Roa Bastos y Manuel Rivas a Mario Benedetti y Julio Llamazares». El País (Babelia 212), 11-11, 126.

\section{Hispanoamérica}

A) Obras

ARENAS, Reinaldo (1990). Viaje a La Habana. Madrid: Mondadori. Reseña: Marco, Joaquín (1991). ABC Literario 523, 9-2, VI.

ARLT, Roberto (1994). El criador de gorilas. Un viaje terrible. Madrid: Alianza (Prólogo de Teodosio Fernández). Reseña: Sorela, Pedro (1994). «El regreso de un gran olvidado. Se recuperan dos obras del escritor argentino Roberto Arlt». El País (Babelia 151), 10-9, 8.

Bioy CASARES, Adolfo (1991). Una muñeca rusa. Barcelona: Tusquets. Reseñas: Marco, Joaquín (1991). ABC Literario 529, 23-3, VII; Fernández Sastre, Roberto (1991). «La lección del maestro. "La muñeca rusa", un magistral compendio del arte de narrar cuentos». El País Libros 287, 14-4, 3.

6 Al igual que en el volumen Cuentos modernistas, esta antología aparece citada también en el apartado de «antologías» del grupo de literatura hispanomericana, por el mismo motivo. 
CoHEN, Marcelo (1992). El fin de lo mismo. Madrid: Anaya \& Mario Muchnik. Reseña: Ayala-Dip, J. Ernesto (1992). «Con la materia de nuestro tiempo. Marcelo Cohen publica cinco largo relatos que exploran los deseos intraductibles». El País (Babelia 40), 25-7, 10.

Demichel, Tulio H. (1994). Agua herida. México: Editorial Vuelta. Reseña: García de la Concha, Víctor (1995). ABC Cultural 168, 20-1, 8.

EDWARDS, Jorge (1993). Fantasmas de carne y hueso. Barcelona: Tusquets. Reseñas: Marco, Joaquín (1993). ABC Cultural 73, 26-3, 11; GarcíaPosada, Miguel (1993). «“¿Qué nos ha pasado a todos nosotros?”. Jorge Edwards reflexiona sobre la reciente historia de Chile». El País (Babelia 78), 9/10-4, 8.

FuENTES, Carlos (1993). El naranjo. Madrid: Alfaguara. Reseña: Vázquez Rial, Horacio (1993). «Un proyecto ético y estético. Las dos vertientes de Carlos Fuentes, narrador y ensayista». El País (Babelia 101), 18-9, 9.

GARCíA MÁrQUEZ, Gabriel (1992). Doce cuentos peregrinos. Madrid: Mondadori. Reseñas: García-Posada, Miguel (1992). «La magia de la belleza y del horros. El fondo trágico de García Márquez, en su nueva colección de relatos». El País (Babelia 40), 25-7, 9-11; Lázaro Carreter, Fernando (1992). ABC Cultural 39, 31-7, 7; S/A (1992). ABC Cultural 60, 24-12, 18. GARMENDIA, Julio (1995). La tierra de muñecos. La tuna de oro. Barcelona: Montesinos. Reseña: Peña, Luis de la (1995). «Descubrir a Julio Garmendia. Excelente oportunidad para leer a este escritor venezolano, precursor del realismo mágico e injustamente olvidado en España». El País (Babelia 219), 30-12, 10.

HERNÁNDEZ, Filisberto (1993). Nadie encendía las lámparas. Madrid: Cátedra. Reseña: Ayala-Dip, J. Ernesto (1993). «Luces y sombras». El País (Babelia 97), 21-8, 8.

KoCIANCICH, Vlady (1991). Todos los caminos. Madrid: Espasa-Calpe. Reseñas: R[oberto] F[ernández] Sastre (1991). El País Libros 291, 12-5, 11; Marco, Joaquín (1991). ABC Literario 537, 18-5, XII.

MastretTA, Ángeles (1991). Mujeres de ojos grandes. Barcelona: Seix Barral. Reseña: Marco, Joaquín (1991). ABC Literario 539, 1-6, VIII. MuJicA LÁINEZ, Manuel (1994). Cuentos inéditos. Madrid: Ollero \& Ramos. Reseñas: J[avier] G[oñi] (1994). «Un hombre de mundo. Los cuentos inéditos de Mujica Láinez». El País (Babelia 156), 15-10, 14; Lázaro Carreter, Fernando (1994). ABC Cultural 155, 21-10, 7.

Orozco, Olga (1991). La oscuridad es otro sol. Valencia: Pre-Textos. Reseña: Marco, Joaquín (1991). ABC Cultural 7, 20-12, 8.

PeYrou, Óscar (1992). Máscaras de polvo. Madrid: Editorial Verbum. Reseña: Basanta, Ángel (1992). ABC Cultural 39, 31-7, 10.

RAMíREZ, Sergio (1994). Charles Atlas también muere. Barcelona: Mondadori. Reseña: Marco, Joaquín (1994). ABC Cultural 130, 29-4, 10. 
Rey Rosa, Rodrigo (1992). Cárcel de árboles. El salvador de buques. Barcelona: Seix Barral. Reseña: Marco, Joaquín (1992). ABC Cultural 18, 6$3,9$.

REY RosA, Rodrigo (1992). El cuchillo del mendigo. El agua inquieta. Barcelona: Seix Barral. Reseña: Marco, Joaquín (1992). ABC Cultural 18, 63,9 .

TORRES BODET, Jaime (1992). El juglar y la domadora. México: Colegio de México. Reseña: Marco, Joaquín (1992). ABC Cultural 40, 7-8, 9.

\section{B) Antologías}

ARENAS, Reinaldo (1995). Adiós a mamá. Barcelona: Altera. Reseña: Goñi, Javier (1995). «Reinaldo Arenas, Eternamente en Fuga. Recopilación de textos y relatos cortos de uno de los escritores cubanos más apasionados e intensos». El País (Babelia 219), 30-12, 10.

BIOY CASARES, Adolfo (1991). La invención y la trama. Barcelona: Tusquets (Edición de Marcelo Pichón). Reseña: Marco, Joaquín (1991). ABC Literario 543, 29-6, VI.

CABrera Infante, Guillermo (1995). Delito por bailar el chachachá. Madrid: Alfaguara. Reseña: Puig, Valentí (1995). ABC Cultural 186, 26$5,13$.

CoRTÁZAR, Julio (1994). Cuentos completos. Madrid: Alfaguara, 2 vols. Reseñas: Rojo, José Andrés (1994). «Vencer al tiempo». El País (Babelia 127), 26-3, 11; Basanta, Ángel (1994). ABC Cultural 128, 15-4, 11.

MUTIS, Álvaro (1993). Empresas y tribulaciones de Maqroll el Gaviero. Madrid: Siruela, 2 vols. Reseña: Conte, Rafael (1993). ABC Cultural 87, 2-7, 9 .

ONETTI, Juan Carlos (1994). Obras completas. Madrid: Alfaguara (Prólogo de Antonio Muñoz Molina). Reseñas: García-Posada, Miguel (1994). «Los cuentos de Santa María. Todos los magistrales relatos de Onetti, en un solo volumen». El País (Babelia 123), 26-2, 94; Conte, Rafael (1994). $A B C$ Cultural 126, 1-4, 9.

QUIROGA, Horacio (1991). Cuentos. Madrid: Cátedra. Reseña: S/A (1991). $A B C$ Literario 534, 27-4, XIV.

RibeYro, José Ramón (1994). Cuentos completos. Madrid: Alfaguara (1994). Reseñas: Goñi, Javier (1994). «El desembarco de un clásico. Presentación de dos libros de José Ramón Ribeyro». El País (Babelia 137, 5-4, 9); Marco, Joaquín (1994). ABC Cultural 143, 29-7, 11.

RiBEYRo, José Ramón (1994). Antología personal. México: FCE. Reseña: Marco, Joaquín (1994). ABC Cultural 143, 29-7, 11.

VV.AA. (1992). Buenos Aires. Una antología de la nueva ficción argentina. 
Barcelona: Anagrama (Edición de Juan Forn). Reseñas: Marco, Joaquín (1992). ABC Cultural 17, 28-2, 12; Ayala-Dip, J. Ernesto (1995). «Arte de ilusionistas». El País (Babelia 22), 14-3, 15.

VV.AA. (1992). Antología del cuento hispanoamericano del siglo XX. Madrid: Alianza Editorial (Selección de José Miguel Oviedo), 2 vols. Reseña: Marco, Joaquín (1992). ABC Cultural 55, 20-11, 11.

VV.AA. (1994). Cuentos modernistas. Madrid: Ed. Popular/Unesco. Reseña: T[rinidad] L[ópez] S[otelo] (1994. ABC Cultural 139, 1-7, 22.

VV.AA. (1995). Cuentos de fúltbol. Madrid: Alfaguara (Selección de Jorge Valdano). Reseña: Goñi, Javier (1995). «La seducción de la esfera. Una recopilación de relatos en los que el fútbol es dueño y señor del texto. Desde Roa Bastos y Manuel Rivas a Mario Benedetti y Julio Llamazares». El País (Babelia 212), 11-11, 12.

\section{TRADUCCIONES}

\section{Otras lenguas nacionales de España ${ }^{7}$}

\subsection{Catalán}

A) Obras

MARí, Antoni (1993). El vaso de plata. Valencia: Pre-Textos. Reseña: Á[ngel] B[asanta] (1993). ABC Cultural 85, 18-6, 10.

Monzó, Quim (1994). El porqué de las cosas. Barcelona: Anagrama (Traducción de Marcelo Cohen). Reseñas: X. M. (1994). «Brevedad y calidad». El País (Babelia 120, 5-2, 31); Basanta, Ángel (1994). ABC Cultural 122, 4-3, 10.

PlA, Josep (1992). La vida amarga. Barcelona: Destino (Traducción de Josep Daurella). Reseñas: Conte, Rafael (1992). ABC Cultural 54, 13-11, 9; Trapiello, Andrés (1992). «Los naranjales de Pla. La narrativa breve del maestro ampurdanés». El País (Babelia 58), 21-11, 11.

PALOL, Miquel de (1993). Entre hélices. Barcelona: Destino (Traducción de Paulina Fariza). Reseña: Basanta, Ángel (1993). ABC Cultural 84, 11-6, 10.

SALADRIGAS, Robert (1991). Historias a mitad de camino. Barcelona: Destino. Reseña: Solé, María (1991). ABC Cultural 19, 13-3, 9.

7 No se incluyen dentro de este apartado libros de cuentos en vasco, puesto que no he encontrado ninguna reseña de volúmenes en dicha lengua. 
B) Antologías

RIERA, Carmen (1991). Te dejo el mar. Madrid: Austral. Reseña: S/A (1991). $A B C$ Literario 555, 21-9, XIV.

\subsection{GALLEGO}

Obras

Méndez FerRín, Xosé Luis (1994). Arraianos. Barcelona: Ronsel (Traducción de Luisa Castro). Reseña: Basanta, Ángel (1994). ABC Cultural $144,5-8,9$.

\section{Las lenguas más traducidas}

\subsection{Inglés}

A) Obras

ALEXIE, Sherman (1994). La pelea celestial del llanero solitario y Toro. Barcelona: Muchnik (Traducción de Marco Aurelio Galmarini). Reseña: Marín, Juan (1994). «Indios lejanos, tribus próximas. Los sorprendentes relatos de Sherman Alexie». El País (Babelia 164), 10-12, 11.

AlfaU, Felipe (1991). Cuentos españoles de antaño. Madrid: Siruela (Traducción y prólogo de Carmen Martín Gaite). Reseñas: Senabre, Ricardo (1991). ABC Cultural 8, 27-12, 11; Ugalde, José Antonio (1992). «Alfau, cuentista. Un ejercicio lúdico del autor de Locos». El País (Babelia 14), $18-1,12$.

ANGulo, Jaime de (1993). Cuentos indios. Madrid: Hiperión (Traducción de Alejandro Valero). Reseñas: S/A (1993). El País (Babelia 69), 6-2, 17; Castro, Luisa (1993). ABC Cultural 72, 19-3, 13.

AUSTER, Paul (1994). El cuaderno rojo. Barcelona: Anagrama (Traducción y prólogo de Justo Navarro). Reseña: Gurpegui, José Antonio (1994). ABC Cultural 130, 29-4, $12^{8}$.

BeLlow, Saul (1993). Un recuerdo que dejo. Madrid: Espasa Calpe (Traducción de John Dougall). Reseña: Hernanz, Beatriz (1993). ABC Cultural $85,18-6,12$.

${ }^{8}$ Esta reseña aparece incompleta en el periódico, por lo que los datos que faltaban se han obtenido tras consultar el ISBN. 
BERGER, John (1992). Una vez en Europa. Madrid: Alfaguara (Traducción de Pilar Vázquez). Reseña: Rojo, José Andrés (1992). «Las catástrofes del amor, John Berger, en el corazón del mundo». El País (Babelia 20), 29-2, 17.

BIERCE, Ambrose (1992). Cuentos de soldados y civiles. Barcelona: Edhasa (Traducción de Jorge Ruffinelli). Reseñas: Gurpegui, José Antonio (1992). ABC Cultural 40, 7-8, 16; Ayala-Dip, J. Ernesto (1992). «Las absurdas hazañas de los héroes. El pesimismo edificante de los cuentos de Ambrose Bierce». El País (Babelia 53), 17-10, 11.

Bowles, Paul (1993). Palabras ingratas. Madrid: Alfaguara (Traducción de R. Rey Rosa). Reseña: Marco, Joaquín (1993). ABC Cultural 79, 7-5, 12. BRODKEY, Harold (1991). Relatos a la manera casi clásica. Barcelona: Anagrama (Traducción de Damián Alou). Reseña: Palol, Miguel (1991). El País (Babelia 11), 28-12, 13.

Bukowsky, Charles (1995). Peleando a la contra. Barcelona: Anagrama (Varios traductores). Reseña: Gurpegui, José Antonio (1995). ABC Cultural 182, 28-4, 11.

CARRINGTON, Leonora (1992). El séptimo caballo. Madrid: Siruela (Traducción de Francisco Torres Oliver). Reseñas: Sánchez-Ostiz, Miguel (1992). ABC Cultural 25, 24-4, 14; Ugalde, José Antonio (1992). «El vuelo libre de la imaginación. La escritura evanescente y enigmática de Leonora Carrington». El País (Babelia 30), 16-5, 15.

CARver, Raymond (1994). Short Cuts. Barcelona. Anagrama. Reseña: N[uria] A[zancot] (1994). ABC Cultural 130, 29-4, 19.

CHABON, Michael (1995). Un mundo modelo. Barcelona: Anagrama (Traducción de Mariano Antolín Rato). Reseña: Gurpegui, José Antonio (1995). $A B C$ Cultural 203, 22-9, 14.

CHATwIN, Bruce (1991). ¿Qué hago yo aquí? Barcelona: Muchnik (Traducción de Alberto Cardín). Reseña: Enzansberger, Hans Magnus (1991). «Siempre en marcha. Se publica el libro póstumo de Bruce Chatwin, viajero, escritor y radical». El País Libros 294, 2-6, 1 y 6.

Cisneros, Sandra (1992). Una casa en Mango Street. Barcelona: Ediciones B (Traducción de Enrique de Hériez). Reseña: Marco, Joaquín (1992). $A B C$ Cultural 31, 5-6, 12.

CisNeros, Sandra (1992). Érase un hombre, érase una mujer. Barcelona: Ediciones B (Traducción de Enrique de Hériez). Reseñas: Marco, Joaquín (1992). ABC Cultural 31, 5-6, 12; Marín, Juan (1992). «Madurar en tierra de otros. El original mestizaje de Sandra Cisneros». El País (Babelia 43), 8-8, 8 .

COOVER, Robert (1993). Sesión de cine. Barcelona: Anagrama (Traducción de Mariano Antolín Rato). Reseñas: Villanueva, Darío (1993). ABC Cultural 82, 28-5, 13; Barriuso, Jorge (1993). «Todos los cines, el cine. Los 
relatos de Robert Coover invitan a un programa ficticio». El País (Babelia 91), 10-7, 11.

DAHL, Roald (1990). Historias extraordinarias. Barcelona: Anagrama. Reseña: S/A (1991). ABC Literario 519, 12-1, XV.

DAHL, Roald (1992). La venganza es mía. Barcelona: Edhasa. Reseña: N[uria] A[zancot] (1992). ABC Cultural 40, 7-8, 21.

FinN GARNER, James (1995). Cuentos infantiles políticamente correctos. Barcelona: Circe (Traducción de Gian Castelli). Reseña: Gurpegui, José Antonio (1995). ABC Cultural 217, 29-12, 11.

FISHER, M. F. K. (1993). No ahora sino ahora. Madrid: Anaya \& M. Muchnik (Traducción de M. Cohen). Reseña: Hernanz, Beatriz (1993). ABC Cultural 80, 14-5, 11.

FoRSYTH, Frederick (1991). El manipulador. Barcelona: Plaza \& Janés (Traducción de Pedro Gálvez). Reseña: Navarro, Justo (1991). ABC Literario 560, 26-10, VII.

Gallant, Mavis (1993). En tránsito. Barcelona: Sirmio (Traducción de Paloma Lago). Reseña: Barriuso, Jorge (1993). «Destellos deslumbrantes». El País (Babelia 72), 27-2, 12.

GORDIMER, Nadine (1992). El salto. Barcelona: Ediciones B (Traducción de Víctor Pozanco). Reseña: López de Lamadrid (1992). «El desafío de una realidad multiforme. Nadine Gordimer refleja las contradicciones de su país en sus últimos relatos». El País (Babelia 29), 2-5, 12.

HAWTHORNE, Nathaniel (1995). Leyendas del bosque frondoso. Madrid: Miraguano (Traducción de J. Kozer). Reseña: Gurpegui, José Antonio (1995). ABC Cultural 199, 25-8, 11.

HARRISON, Jim (1995). Leyendas de pasión. Barcelona: Ediciones B (Traducción de Luis Alvear). Reseña: Gurpegui, José Antonio (1995). ABC Cultural 192, 7-7, 11.

HighSMITH, Patricia (1991). Sirenas en el campo de golf. Barcelona: Anagrama. Reseña: A[dolfo] C[astaño] (1992). ABC Cultural 10, 10-1, 20.

HowARD, Robert E. (1995). Las aventuras de Salomón Kane. Madrid: Anaya (Traducción de J. Martín Lalanda). Reseña: Cuenca, Luis Alberto de (1995). ABC Cultural 173, 24-2, 13.

IRVING, Washington (1991). Cuentos de la Alhambra. Madrid: Espasa-Calpe (Traducción de Ventura Traveset; Edición de Antonio Gallego Morell). Reseña: S/A (1991). ABC Literario 542. 22-6, XV.

JACKSON, Shirley (1991). La lotería. Barcelona: Edhasa (Traducción de Hernán Sabaté). Reseña: Gurpegui, José Antonio (1991). ABC Cultural 5, 6-12, 42. JAMES, Henry (1993). La tercera persona y otros relatos fantásticos. Madrid: Rialp (Traducción de Luis Magrinyá). Reseñas: Sorela, Pedro (1993). «Henry James, el terco. Los diferentes cuentos del novelista». El País (Babelia 89), 26-6, 12. Cuenca, Luis Alberto de (1993), ABC Cultural 79, 7-5, 12. 
KaVAN, Anna (1993). Mi alma en China. Madrid: Grijalbo/Mondadori (Traducción de Laura Freixas). Reseña: Navarro, Justo (1993). ABC Cultural 78, 30-4, 10.

KING, Stephen (1994). Pesadillas y alucinaciones. Barcelona: Grijalbo (Traducción de Bettina Blanch). Reseña: Navarro, Justo (1994). ABC Cultural 148, 2-9, 16.

LAURENCE. Margaret (1994). Un pájaro en la noche. Barcelona: Muchnik (Traducción de M. A. Galmarini). Reseña: Navarro, Justo (1994). $A B C$ Cultural 153, 7-10, 13.

LuCAs, Russell (1992). Noches en Mongini's. Barcelona: Anagrama (Traducción de Luis Murillo). Reseña: Hernanz, Beatriz (1992). ABC Cultural 50, 16-10, 14.

MATTHIESSEN, Peter (1993). La laguna Estigia y otros relatos. Madrid: Siruela (Traducción de José Luis López Muñoz). Reseña: Rojo, José Andrés (1993). «El hombre sitiado. Los relatos de Peter Matthiessen». El País (Babelia 111), 27-11, 13.

MunRo, Alice (1990). Las lunas de Júpiter. Barcelona: Versal (Traducción de Esperanza Pérez Moreno). Reseña: Obiol, María José (1991). «Almíbar de hiel». El País Libros 279, 17-2, 3.

MunRo, Alice (1991). El progreso del amor. Madrid: Debate (Traducción de Flora Casas). Reseña: Obiol, María José (1991). «Almíbar de hiel». El País Libros 279, 17-2, 3.

MunRo, Alice (1991). Amistad de juventud. Barcelona: Versal (Traducción de Esperanza Pérez Moreno). Reseñas: Navarro, Justo (1991). ABC Literario 540, 8-6, VI; Ayala-Dip, J. Ernesto (1991). «Cuentos lúcidos». El País Libros 308, 8-9, 2.

NABOKov, Vladimir (1992). Una belleza rusa. Barcelona: Anagrama (Traducción de Rafael Ruiz de la Cuesta). Reseña: Marías, Javier (1993). «El canon Nabokov. Una obra cuentística clásica e innovadora que resume todas las tendencias». El País (Babelia 66), 16-1, 11.

O'BRIEN, Dan (1991). Los leones marinos. Barcelona: Noguer (Traducción de Ángel Bofarull). Reseña: Gurpegui, José Antonio (1991). ABC Literario 557, 5-10, $\mathrm{X}$.

Ozick, Cynthia (1992). El chal. Barcelona: Montesinos (Traducción de Daniela Stein). Reseña: Gurpegui, José Antonio (1992). ABC Cultural $24,17 / 18-4,15$.

Plath, Sylvia (1995). Johnny Panic y la Biblia de los sueños. Madrid: Alianza (Traducción de José Luis López). Reseña: Gurpegui, José Antonio (1995). ABC Cultural 210, 10-11, 12.

PORTER, Katherine Anne (1990). Judas en flor. Barcelona: Destino (Traducción de Horacio Vázquez Rial). Reseña: Panero, Juan Luis (1991). «La oscura, inexplicable muerte del amor». El País Libros 277, 3-2, 2. 
PORTER, Katherine Anne (1992). Pálido caballo, pálido jinete. Barcelona: Destino (Traducción de Maribel de Juan). Reseñas: Hernanz, Beatriz (1993). ABC Cultural 64, 22-1, 12; Ayala-Dip, J. Ernesto (1993). «Atmósferas de irrealidad». El País (Babelia 71), 20-2, 12.

STEINER, George (1993). Pruebas y Tres parábolas. Barcelona: Destino (Traducción de Héctor Silva). Reseña: Munné, Antoni (1993). «El argumento de la idea. Cuatro narraciones de un maestro del ensayo, George Steiner». El País (Babelia 110), 20-11, 10.

STYRON, William (1995). Una mañana en la costa. Barcelona: Mondadori (Traducción de María Antonia Menini). Reseñas: Villanueva, Darío (1995). ABC Cultural 193, 14-7, 11; Guelbenzu, José María (1995). «Experiencias tempranas. Aparecen tres narraciones de William Styron». El País (Babelia 196), 15-7, 9.

WALPOLE, Horace (1995). Cuentos jeroglíficos. Madrid: Alianza (Prólogo y notas de Luis Alberto de Cuenca). Reseña: Pujol, Carlos (1995). ABC Cultural 199, 25-8, 11.

Welty, Eudora (1991). Las manzanas doradas. Barcelona: Anagrama (Traducción de B. McShane y J. Alfaya). Reseña: Puig, Valentí (1991). ABC Literario 527, 9-3, VII.

WiDEMANN, John Edgar (1990). Fiebre. Barcelona: Versal (Traducción de David Malague). Reseña: Gurpegui, José Antonio (1991). ABC Literario 526, 2-3, X.

WodeHOUSE, P. G. (1991). Ukridge. Barcelona: Versal (Traducción de Esteban Riambau). Reseña: España, Ramón de (1991). «De criados y gorrones. P. G. Wodehouse, remedio para pesimistas». El País Libros, 290, $5-5,2$.

B) Antologías

AsImov, Isaac (1993). Cuentos completos. Barcelona: Ediciones B. Reseña: J[avier] R[ubio] (1993). ABC Cultural 69, 26-2, 22.

BASHEVIS SINGER, Isaac (1992). Un amigo de Kafka y otros relatos. Madrid: Cátedra (Traducción de Pilar Alonso). Reseña: López de Lamadrid, Claudio (1992). «La ambición de un escritor. Tres libros permiten regresar a Isaac Bashevis Singer». El País (Babelia 20), 29-2, 15.

Bowles, Paul (1995). Cuentos escogidos. Madrid: Alfaguara (Traducción de Guillermo Lorenzo, Héctor Silva y Rodrigo Rey Rosa. Prólogo de J. J. Armas Marcelo). Reseñas: Marco, Joaquín (1995). ABC Cultural 187, 26, 13; Freixas, Laura (1995). «Retrato del artista itinerante. Se publican cartas y cuentos de Paul Bowles, el escritor viajero». El País (Babelia 194), 1-7, 11. 
CHANDLER, Raymond (1995). Obras completas I y II. Barcelona: Debate (Varios traductores). Reseña: Marco, Joaquín (1995). ABC Cultural 195, 28-7, 7.

Clarke, Arthur C. y otros (1992). Dinosaurios. Barcelona: Grijalbo (Traducción de Carme Campos). Reseñas: Antón, Jacinto (1992). «Queridos, fascinantes, terribles lagartos. Una nueva mirada sobre los dinosaurios». El País (Babelia 46), 29-8, 8; Cuenca, Luis Alberto de (1992). ABC Cultural 51, 23-10, 14.

GREENE, Graham (1991). La última palabra. Barcelona: Seix Barral (Traducción M. Girugeda y A. M. de la Fuente). Reseñas: S/A (1991). ABC Literario 541, 15-6, XIV; Ayala-Dip, J. Ernesto (1991). «13 relatos de Graham Greene. El propio escritor británico seleccionó los cuentos un año antes de morir». El País Libros 304, 11-8, 3.

LOVECRAFT, H. P. (1991). La noche del océano. Madrid: Edaf (Traducción de José María Nebreda). Reseñas: Cuenca, Luis Alberto de (1991). $A B C$ Literario 536, 11-5, X; Antón, Jacinto (1991). «La sombra de Lovecraft. Una selección de textos inéditos, en la estela del centenario del escritor». El País Libros 294, 2-6, 7.

SHELLEY, Mary W. (1993). Cuentos góticos. Madrid: Valdemar (Traducción de Elías Sarhan). Reseña: Cuenca, Luis Alberto de (1993). ABC Cultural 84, 11-6, 13.

SMITH, Clark Ashton (1992). Los mundos perdidos. Madrid: Edaf (Traducción de Arturo Villarubia). Reseña: Cuenca, Luis Alberto de (1992). ABC Cultural 24, 17-4, 11.

TAGORE, Rabindranath (1994). Historias cortas. Barcelona: Apóstrofe Pokhara. Reseña: T[rinidad] L[eón] S[otelo] (1994). ABC Cultural 138, 24$6,23$.

YeATs, William Butler (1991). Espectros y otros cuentos fantásticos. Palma de Mallorca: José J. de Olañeta (Edición de Carmen Bravo-Villasante). Reseña: S/A (1991). ABC Literario 548, 3-8, XIV.

VV.AA. (1991). Vamps. Madrid: Valdemar (Recopilación de Martín H. Greenberg y Charles G. Waught. Traducción de Albert Solé). Reseña: Antón, Jacinto (1991). «Espejos para Drácula. Un ensayo, una novela y dos antologías de relatos demuestran la vitalidad del mito del vampiro». $E l$ País Libros 304, 11-8, 4-5.

VV.AA. (1991). Vampiros. Barcelona: Robin Book (Traducción de Josep Rovira). Reseña: Antón, Jacinto (1991). «Espejos para Drácula. Un ensayo, una novela y dos antologías de relatos demuestran la vitalidad del mito del vampiro». El País Libros 304, 11-8, 4-5.

VV.AA. (1992). Venganza. Barcelona: Edhasa (Traducción de Mireia Bofill). Reseña: T[rinidad] de León-Sotelo (1992). ABC Cultural 23, $10-4,10$. 
VV.AA. (1992). Historias para morirse. Barcelona: Edhasa (Selección de Alfred Hitchcock). Reseña: T. L. (1992). ABC Cultural 53, 6-11, 22.

VV.AA. (1992). Drácula insólito. Barcelona: Timun Mas (Traducción de F. Rodríguez de Lecea). Reseña: Antón, Jacinto (1993). «El nido del vampiro. Dos antologías muestran los orígenes y desarrollos del mito de Drácula». El País (Babelia 69), 6-2, 15.

VV.AA. (1991) ${ }^{9}$. Diez escritoras indias. Barcelona: Icaria (Traducción de Elena Villaón). Reseña: León-Sotelo, Trinidad de (1991). ABC Literario $548,3-8$, VI.

Woolf, Virginia (1994). Relatos completos. Madrid: Alianza (Traducción de Catalina Martínez Muñoz). Reseñas: Puig, Valentí (1994). ABC Cultural 161, 2-12, 7; Guelbenzu, José María (1994). «Un precioso regalo. La triple actualidad bibliográfica de Virginia Woolf». El País (Babelia 167), 29-12, 7.

\subsection{Francés}

\section{A) Obras}

BEN Jelloum, Tahar (1994). El ángel ciego. Barcelona: Península (Traducción de Malika Embarek). Reseña: Bayón, Miguel (1994). «Un Mediterráneo podrido. Tahar Ben Jelloum asoma al paisaje de la Mafia». El País (Babelia 129), 9-4, 13.

CARTARESCU, Mircea (1993) ${ }^{10}$. El sueño. Barcelona: Seix-Barral (Traducción de Pilar Giralt Gorina). Reseña: Vidal, Juan Carlos (1993). «Las catacumbas de la razón. Mircea Cartarescu, más allá de la literatura fantástica». El País (Babelia 91), 10-7, 12.

COMMENT, Bernard (1994). Idas y venidas. Madrid: Siruela (Traducción de Carlos Manzano). Reseña: Castro, Pilar (1995). ABC Cultural 174, 3-3, 12. EliAdE, Mircea (1994). El burdel de las gitanas. Madrid: Siruela (Traducción de M. Teresa Gallego y M. Isabel Reverte). Reseña: Antón, Jacinto (1994). «Sólo para iniciados. Siruela publica tres relatos cortos de Mircea Eliade». El País (Babelia 140), 25-6, 12.

Francia, María de (1993). Les lais. Barcelona: Sirmio (Edición del texto, traducción y notas de Ana María Holzbacher). Reseña: García Gual, Carlos (1993). «Mágicos relatos de amor y muerte. María de Francia, una refinada cuentista». El País (Babelia 81), 1-5, 16.

9 Aunque los relatos fueron escritos en las lenguas originales de sus autoras -malayalam, punjabi, urdu, tamil o hindi, entre otras-, la traducción se ha realizado del inglés.

10 A pesar de que este autor y Mircea Eliade son rumanos, se incluyen en este apartado, puesto que las respectivas traducciones se han realizado del francés. 
GHELDERODE, Michel de (1992). Sortilegios. Barcelona: Lumen (Traducción de F. Moreno Castillo). Reseñas: Castro, Pilar (1992). ABC Cultural 38, 24-7, 14; García Sánchez, Javier (1992). «La vida secreta que bulle. Michel de Ghelderode, un olvidado de su siglo». El País (Babelia 56), 14-11, 13.

GRACQ, Julien (1993). En el castillo de Argol. Madrid: Siruela (Traducción de Mauro Armiño). Reseña: Conte, Rafael (1993). ABC Cultural 83, 28$5,11$.

HraBAL, Bohumil (1994). Las desventuras del viejo Werther. Barcelona: Península (Traducción de M. García Barris). Reseña: Villanueva, Darío (1994). ABC Cultural 131, 6-5, 13.

LEAUTAUD, Paul (1991). Amores. Barcelona: Versal (Traducción de Esteban Riambau). Reseña: Demicheli, Tulio H. (1991). ABC Literario 553, 7-9, VI.

NAVARRA, Margarita de (1991). Heptamerón. Madrid: Cátedra (Traducción de María Soledad Arredondo). Reseña: García Gual, Carlos (1991). «Reina y cuentista. Nueva y ajustada traducción de los relatos de Margarita de Navarra». El País (Babelia 9), 14-12, 14.

TOURNIER, Michel (1991). Medianoche de amor. Madrid: Alfaguara (Traducción de S. Martín Bermúdez). Reseña: Marco, Joaquín (1991). ABC Literario 558, 13-10: III.

B) Antologías

BRETON, André (1991). Antología del humor negro. Barcelona: Anagrama. Reseña: S/A (1991). ABC Cultural 2, 15-11, 20.

DURAS, Marguerite (1994). Escribir. Barcelona: Tusquets (Traducción de Ana María Moix). Reseña: Pereda, Rosa (1994). «Leer a la Duras. Recopilación de cinco textos de la autora de "El amante"». El País (Babelia 159), 5-11,9.

PROSPER, Merimée (1995). Lokis y otros relatos fantásticos. Barcelona: Alba (Traducción de S. Cantero Garrido. Prefacio de G. Ramos). Reseña: Pujol, Carlos (1995). ABC Cultural 205, 6-10, 13.

VV.AA. (1994). Fabliaux. Cuentos franceses medievales. Madrid: Cátedra (Ed. bilinguie de F. de Casas). Reseña: Lázaro Carreter, Fernando (1994). ABC Cultural 149, 9-9, 7.

YouRCENAR, Marguerite (1995). Cuento azul. Madrid: Alfaguara (Traducción de Emma Calatayud). Reseña: Pereda, Rosa (1995). «El sueño del color». El País (Babelia 178), 18-3, 11. 


\subsection{Italiano}

\section{A) Obras}

Boccacio, Giovanni (1994). El Decamerón. Madrid: Cátedra (Ed. de M. Hernández). Reseña: R[afael] C[onte] (1994). ABC Cultural 139, 1-7, 22.

BORGESE, Giuseppe-Antonio (1992). Retrato de mujeres guapas. Barcelona:

Muchnik. Reseña: T. L. (1992). ABC Cultural 50, 16-10,22.

CALvino, Italo (1994). Memoria del mundo y otras cosmicómicas. Madrid:

Siruela (Traducción de Aurora Bernárdez). Reseña: Villanueva, Darío (1994). ABC Cultural 161, 2-12, 11.

PRESSBURGer, Giorgio (1991). La ley de los espacios en blanco. Barcelona:

Destino (Traducción de Juana Bignozzi). Reseña: Ugalde, José Antonio (1991). «Enigmas corporales». El País Libros 294, 2-6, 4.

RoBERTO, Federico de (1995). Atestados. Madrid: Anaya/Mario Muchnik (Traducción de José Ramón Monreal). Reseñas: Pujol, Carlos (1995). $A B C$ Cultural 211, 17-11, 13; J[osé] E. A[yala] -D[ip] (1995). «Relatos casi fotográficos de Federico de Roberto». El País (Babelia 216), 9-12, 10.

SERAO, Matilde (1994). Flor de pasión. Madrid: Lípari (Traducción de R. del Valle Inclán). Reseña: Castro, Pilar (1994). ABC Cultural 145, 12-8, 10. TABUCCHI, Antonio (1991). Los volátiles del Beato Angélico. Barcelona: Anagrama. Reseña: García-Posada, Miguel (1991). ABC Literario 523, 9-2, III.

TABUCCHI, Antonio (1993). El ángel negro. Barcelona: Anagrama (Traducción de C. Gumpert y J. González). Reseñas: Navarro, Justo (1993). $A B C$ Cultural 66, 5-2, 13; García-Posada, Miguel (1993). «Ángeles y sueño. El mal y lo fantástico, en el último libro de relatos del escritor italiano». El País (Babelia 71), 20-2, 15.

TAMARo, Susanna (1993). Para una voz sola. Barcelona: Seix-Barral (Traducción de Atilio Pentimalli). Reseña: Navarro, Justo (1993). ABC Cultural 74, 2-4, 13.

B) Antologías

Borto, Camilo (1993). Senso y otros relatos. Madrid: Cátedra (Edición de Mónica Fametti. Traducción de Inmaculada Vaca). Reseña: Castro, Pilar (1993). ABC Cultural 112, 24-12, 12.

Calvino, Italo (1993). La gran bonanza de Las Antillas. Barcelona: Tusquets

(Traducción de Aurora Bernárdez). Reseñas: Guelbenzu, José María 
(1993). «El encanto de la fantasía. Más inéditos de Italo Calvino, que resumen 40 años de escritura literaria». El País (Babelia 88), 19-6, 11; Marco, Joaquin (1993). ABC Cultural 87, 2-7, 11.

LANDOLFI, Tommaso (1991). Invenciones. Madrid: Siruela (Selección y prólogo de Italo Calvino. Traducción de Ángel Sánchez Gijón). Reseña: Navarro, Justo (1991). ABC Cultural 4, 29-11, 11.

PAVESE, Cesare (1994). Luchas de jóvenes y otros relatos (1925-1930). Barcelona: Seix Barral (Traducción de Atilio Pentimalli). Reseñas: Navarro, Justo (1994). ABC Cultural 138, 24-6, 13; García-Posada, Miguel (1994). «Contar la desesperación. Publicada en española la obra narrativa juvenil de Pavese». El País (Babelia 141), 2-7, 9.

\subsection{Alemán}

A) Obras

BERNHARD, Thomas (1992). Tentativa de salvamento absurdo. Barcelona: Anagrama (Traducción de Miguel Sáenz). Reseña: García-Posada, Miguel (1992). «El pesimismo de Bernhard en una de sus primeras obras». El País (Babelia 34), 6-6.

BernhARD, Thomas (1993). El carpintero y otros relatos. Madrid. Alianza (Traducción de Miguel Sáenz). Reseñas: Marco, Joaquín (1993). ABC Cultural 92, 6-8, 11; Rojo, Andrés (1993). «El cronista de las catástrofes. Los relatos de madurez y desesperación de Thomas Bernhard». El País (Babelia 98), 28-8, 11.

DöBlin, Alfred (1991). Los de Lobenstein viajan a Bohemia. Barcelona: Destino (Traducción de Javier Orduña). Reseña: Ugalde, José Antonio (1992). ABC Cultural 17, 8-2, 12.

Hofman, Gert (1991). El caballo de Balzac. Barcelona: Edhasa (Traducción de Teófilo de Lozoya). Reseña: Ayala-Dip, J. Ernesto (1991). «Criaturas imaginarias». El País Libros 275, 20-1, 4.

MÜLleR, Herta (1991). En tierras bajas. Madrid: Siruela (Traducción de Juan José del Solar). Reseña: Fernández Sastre, Roberto (1991). «Nueva savia expresionista». El País Libros, 291, 12-5, 2.

UnGar, Hermann (1991). Chicos y asesinos. Barcelona: Seix-Barral (Traducción de A. M. de la Fuente). Reseña: Fernández Sastre, R[oberto] (1991). El País Libros 307, 1-9, 7.

Wolf, Christa (1991). Bajo los tilos. Barcelona: Seix-Barral (Traducción de Marisa Presas). Reseña: García-Posada, Miguel (1991). ABC Literario $542,22-6$, III. 
B) Antologías

BENJAMIN, Walter (1991). Historias y relatos. Barcelona: Península. Reseña: Echevarría, Ignacio (1991). "Benjamin, narrador. "Historia y relatos" reúne narraciones del autor escritas entre 1913 y 1935». El País Libros 287, 14-4, 4-5.

VV.AA. (1992). Cuentos románticos alemanes. Madrid: Siruela (Edición de Hugo Von Hofmannsthal. Traducción de María Antonia Seijo). Reseña: Marí, Antoni (1992). «El enigma de la imaginación, la razón y la vida». El País (Babelia 63), 25-12, 8.

\section{Miscelánea de varios idiomas}

Antologías

ANÓNIMO (1992). Caperucitas, cenicientas y marisabidillas. Barcelona: Edhasa (Selección de Angela Carter). Reseña: N[uria] A[zancot] (1992). $A B C$ Cultural 33, 19-6, 22.

ANÓNIMO (1995). Catálogo tipológico del cuento folclórico. Madrid: Gredos (Edición de Julio Camarena y Maxime Chevalier). Reseña: Cuenca, Luis Alberto de (1995). ABC Cultural 212, 24-11, 13.

VV.AA. (1990). La mano de la hormiga. Madrid: Fugaz (Selección de Antonio Fernández Ferrer). Reseña: Méndez, José (1991). ABC Literario 523, 9-2, VI.

VV.AA. (1992). Antología del cuento triste. Barcelona: Edhasa (Selección de Augusto Monterroso y Bárbara Jacobs). Reseñas: F. L. (1992). ABC Cultural 60, 24-12, 22; Ayala-Dip, J. Ernesto (1993). «Brevedad de la tristeza». El País (Babelia 74), 13-3, 10.

VV.AA. (1992). Vampiros. Madrid: Siruela (Traducción de Miguel Sáenz, Torres Oliver, Juan Antonio Molina Fox y Luis Alberto de Cuenca). Reseñas: Antón, Jacinto (1993). «El nido del vampiro. Dos antologías muestran los orígenes y desarrollos del mito de Drácula» 11. El País (Babelia 69), 6-2, 15; Armiño, Mauro (1993). ABC Cultural 68, 19-2, 14.

VV.AA. (1994). El cuento erótico griego, latino e indio. Madrid: Ediciones del Orto (Edición de Francisco Rodríguez Adrados. Ilustraciones de Antonio Mingote). Reseña: Lázaro Carreter, Fernando (1994). ABC Cultural 124, 18-3, 7 .

11 Ver VV.AA. (1992). Drácula insólito. Barcelona: Timun Mas, en «Antologías», del apartado «Inglés». 
VV.AA. (1994). Cuentos europeos. Barcelona: Anagrama. Reseña: Castro, Pilar (1995). ABC Cultural 166, 6-1, 12.

VV.AA. (1995). Cuentos fantásticos del XIX. Madrid: Siruela/Bolsillo (Selección de Italo Calvino). Reseña: T[rinidad] L[eón] S[otelo] (1995). ABC Cultural 197, 11-8, 8.

\section{Las lenguas menos traducidas}

4.1. Ruso

A) Obras

Berberova, Nina (1994). Crónicas de Billancourt. Barcelona: Circe (Traducción de Selma Ancira). Reseña: Castro, Pilar (1994). ABC Cultural $161,2-12,11$.

BERBEROVA, Nina (1995). La orilla eterna. Barcelona: Circe (Traducción de Selma Ancira). Reseña: Hernanz, Beatriz (1995). ABC Cultural 189, 16$6,12$.

Bulgákov, Mijail (1992). Morfina. Barcelona: Anagrama (Traducción de Selma Ancira). Barcelona: Anagrama. Reseña: Prados, Luis (1992). «La soledad del dolor». El País (Babelia 23), 21-3, 14.

Petrushévskaia, Liudmila (1993). Amor inmortal. Madrid: Alianza (Traducción de H. S. Kriúkova y V. Cazcarra). Reseñas: Villanueva, Darío (1993). ABC Cultural 84, 11-6, 11; Bogdanova, Natasha (1993). «Cuentos de la catástrofe cotidiana. La escritura lírica de Luidmila Petrushévskaia». El País (Babelia 88), 19-6, 12.

TóKAVERA, Viktoria (1992). El zigzag del amor. Barcelona: Circe (Traducción de Selma Ancira). Reseña. Castro, Pilar (1992). ABC Cultural 61, 31-12, 11.

Tolstói, Tatiana (1991). Sonámbula en la niebla. Madrid: Grijablo Mondadori (Traducción de Lydia Kúper). Reseñas: Castro, Luisa (1992). $A B C$ Cultural 14, 7-2, 16; Marín, Juan (1992). «Detrás del rostro perplejo. Tatiana Tolstói retrata el presente soviético». El País (Babelia, 17), 8-2-17.

B) Antologías

AfANÁSIEv, Alexandr Nikoláievich (1991). Cuentos prohibidos rusos. Madrid. Alborada Ediciones (Traducción de Mar García y J. Garrote). Reseña: Castro, Luisa (1991). ABC Literario 533, 20-4, VI. 


\subsection{Checo}

\section{Obras}

CAPEK, Karel (1993). Nueve cuentos y uno de propina. Madrid: Siruela (Traducción de J. Mlejnkova y A. Ortiz). Reseña: Castro, Luisa (1993). ABC Cultural 79, 7-5, 13.

Neruda, Jan (1992). Imágenes de la vieja Praga. Barcelona: Juventud. Reseña: S. C. (1992). ABC Cultural 36, 10-7, 19.

NerudA, Jan (1993). Escenas y arabescos. Barcelona: Juventud. Reseña: N[uria] A[zancot] (1993). ABC Cultural 79, 7-5, 22.

\subsection{Chino}

A) Obras

Sung LIN, Pu (1992). Historias fantásticas de un diletante. Madrid: Mondadori (Traducción de Imelda Huang Wang y Enrique Prieto Gatón). Reseña: Higueras, Georgina (1992). «Cuentos chinos». El País (Babelia 40), 18-7, 10.

B) Antologías

VV.AA. Cuentos de la dinastía Tang. Madrid: Miraguano (Traducción de Ediciones Lengua Extranjera de Beijing). Reseña: Cuenca, Luis Alberto de (1992). ABC Cultural 14, 7-2, 15.

\subsection{Polaco}

Obras

MROZEK, Slawomir (1995). La vida difícil. Barcelona: Sirmio (Traducción de Bozena Zaboklicka y Francesc Miravitlles). Reseñas: Rojo, José Andrés (1995). «Ráfagas de literatura en estado puro. "La vida difícil", recopilación de relatos del escritor polaco Slawomir Mrozek». El País (Babelia 194), 1-7, 11; Hernanz, Beatriz (1995). ABC Cultural 194, 21-7, 9.

Shulz, Bruno (1993). Obra completa. Madrid: Siruela (Traducción de Juan Carlos Vidal). Reseña: Conte, Rafael (1994). ABC Cultural 115, 14-1, 13. 


\subsection{Portugués}

Obras

SARAmago, José (1994). Casi un objeto. Madrid: Alfaguara (Traducción de Eduardo Naval). Reseñas: García-Posada, Miguel (1994). ABC Cultural 157, 22-10, 9; Marco, Joaquín (1994). ABC Cultural 158, 11-11, 10.

ToRGA, Miguel (1994). Rúa. Madrid: Alfaguara (Traducción de Eloísa Álvarez). Reseñas: García-Posada, Miguel (1994). «Prodigioso universo. "Rúa", la radical unidad de los relatos del escritor portugués Miguel Torga». El País (Babelia 160), 12-11, 9; Navarro, Justo (1994). ABC Cultural 162, 9-12, 11.

\subsection{Rumano}

Obras

MANEA, Norman (1992). Una ventana hacia la clase trabajadora. Madrid: Grupo Libro 88 (Traducción de D. Stefanescu). Reseña: Rodríguez, Carmen (1992). ABC Literario 49, 9-10, 12.

\subsection{Albanés}

Antologías

VV.AA. (1994). Cuentos populares albaneses. Madrid: Miraguano (Traducción de Ramón Sánchez Lizarralde). Reseña: Cuenca, Luis Alberto de (1994). ABC Cultural 164, 22-12, 12.

\subsection{Hebreo}

Antologías

VV.AA. (1991). Cuentos de los rabinos. Córdoba: El Almendro (Edición de Amparo Alba). Reseña: Azancot, Leopoldo (1991). ABC Literario 555, 21-9, VI.

VV.AA. (1992). Once escritoras israelíes. Barcelona: Icaria (Traducción de A. Bejarano y T. Martínez). Reseña: León-Sotelo, Trinidad de (1992). $A B C$ Cultural 37, 17-7, 12. 
4.9. Sueco

Obras

GUSTAFSSON, Lars (1992). El extraño animal del Norte. Madrid: Anaya \& Mario Muchnik (Traducción de Jesús Pardo). Reseña: Ugalde, José Antonio (1993). «Las piezas del universo, ese gran laberinto. Lars Gustafsson ensaya la ciencia-ficción». El País (Babelia 68), 30-1, 12.

\subsection{Danés}

Obras

Dinesen, Isak (1991). Carnaval. Madrid: Debate (Traducción de Jaime Silva). Reseñas: S/A (1991). ABC Literario 524, 16-2, XIV; M[aría] J[osé] Obiol (1991). El País Libros 281, 3-3, 11.

4.11. Árabe

Obras

VV.AA. (1990). Cuentos de Yehá. Sevilla: Padilla (Recopilación de Tomás García Figueras). Reseña: Cabezas, Juan Antonio (1991). ABC Literario 527, 9-3, IV.

\subsection{Otras (no especificadas)}

Antologías

HedAYAT, Sadeq (1992). El búho ciego y otros relatos. Sabadell: Editorial Ausa (Traducción de R. Lemosín Martel). Reseña: Janés, Clara (1992). «Gotas de tinta o sangre. Tres versiones de un libro de Sadeq Hedayat». El País (Babelia 33), 30-5, 13. 


\section{CONCLUSIONES}

Hasta aquí la bibliografía. Nuestro trabajo, de carácter recopilador, es un intento de acercamiento al cuento contemporáneo, principalmente. La finalidad del mismo radica en proporcionar un corpus bibliográfico para su utilización en posteriores análisis, corpus expuesto en el X Seminario Internacional del Instituto de Semiótica Literaria, Teatral y Nuevas Tecnologías, organizado por la UNED, bajo el título de «El cuento en la década de los noventa». De esta forma, se atiende a la crítica más reciente, difundida en los medios de comunicación periodística durante el tiempo que transcurre entre 1991 y 1995, ambos años inclusive. Se han rastreado los suplementos de $A B C$ Literario y El País Libros, hasta la desaparición de ambos, el 1 de noviembre y el 12 de octubre de 1991, respectivamente, y el $A B C$ Cultural y $B a b e l i a$, que comenzaron sus también respectivas andaduras el 8 de noviembre y el 19 de octubre del año antes citado. La calidad y difusión de los suplementos consultados es suficiente garantía, a nuestro parecer, para encontrar la mayor parte de lo publicado en el género durante esos años.

La tarea se ha traducido, por tanto, en la recopilación de los datos bibliográficos correspondientes a 358 libros, de los cuales 70 han merecido la atención de los críticos de ambos periódicos, por lo que se ha recogido la referencia de 428 reseñas o críticas. El número de libros reseñados, según la lengua de procedencia, es el siguiente:

\begin{tabular}{lccc}
\hline Lengua de origen & Obras & Antologías & Total \\
\hline ESPAÑOL (España) & 135 & 43 & 179 \\
\hline ESPAÑOL (Hispanoam.) & 19 & 13 & 32 \\
\hline CATALÁN & 5 & 1 & 6 \\
\hline GALLEGO & 1 & - & 1 \\
\hline INGLÉS & 52 & 18 & 70 \\
\hline FRANCÉS & 11 & 5 & 16 \\
\hline ITALIANO & 9 & 4 & 13 \\
\hline ALEMÁN & 7 & 2 & 9 \\
\hline MISCELÁNEA & - & 8 & 8 \\
\hline RUSO & 6 & 1 & 7 \\
\hline CHECO & 3 & - & 3 \\
\hline CHINO & 1 & 1 & 2 \\
\hline POLACO & 2 & - & 2 \\
\hline PORTUGUÉS & 2 & - & 2 \\
\hline RUMANO & 1 & - & 1 \\
\hline ALBANÉS & - & 1 & 1 \\
\hline HEBREO & 2 & - & 2 \\
\hline SUECO & 1 & - & 1 \\
\hline DANÉS & 1 & - & 1 \\
\hline ÁRABE & 1 & - & 1 \\
\hline IDIOMA DESCONOCIDO & - & 1 & 1 \\
\hline
\end{tabular}


Lo que gráficamente, queda representado de la siguiente forma:

\section{LIBROS DE CUENTOS SEGÚN LENGUAS DE PROCEDENCIA (1991-1995)}

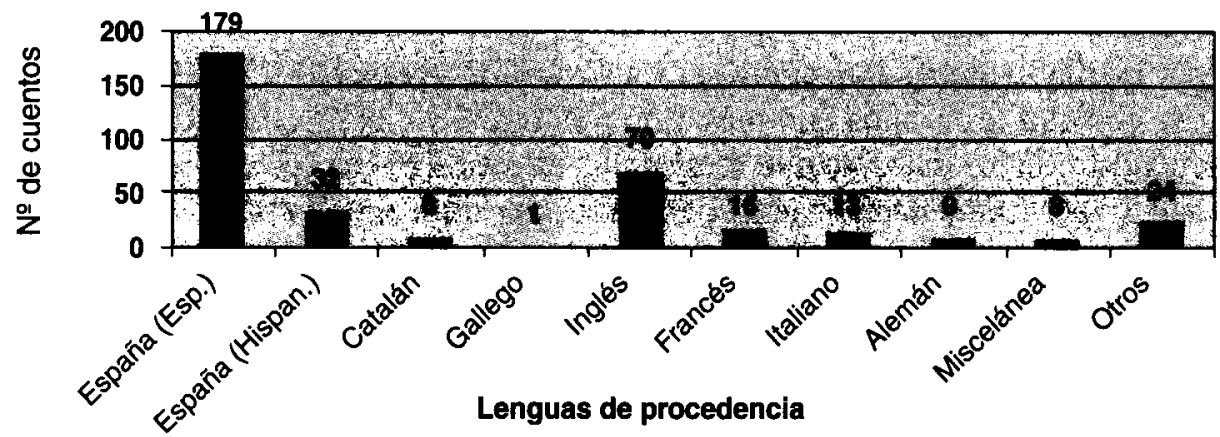

La amplia lista, tanto de libros como de reseñas sobre los mismos, puede ayudar a investigar un género tan poco representado en los estudios literarios hasta hace pocos años. Tal posibilidad viene determinada no sólo por la presentación de un número abundante de libros, sino por lo que de los mismos se dice en las reseñas recogidas. En ellas encontramos información de distinto tipo sobre los libros de relatos, que por la reciente aparición de éstos sería difícil de encontrar en otro lugar: por un lado, información relativa a su contenido, sus aspectos formales y estructurales, su clasificación temática y, por otro, información relacionada con los datos biográficos, trayectoria y significación literarias y bibliografía de sus autores.

Evidentemente, nuestro empeño ahora se queda fuera de aquellos objetivos que tuvieran que ver con un estudio más profundo del género. De momento, y dado el limitado espacio del que disponemos, pretendemos —además de dejar constancia, como hemos dicho, de un listado de cuentosmostrar algunas reflexiones y algunos datos surgidos al tiempo, y como consecuencia, de la confección del corpus bibliográfico:

1. La primera reflexión se ha presentado en el momento de la ordenación de las obras. El repertorio obtenido se ha clasificado en función del idioma del que se ha traducido, que no de origen del texto en algún caso, y dentro de cada uno de estos grupos se ha hecho la distinción entre «obras» y «antologías». Se entiende por esto último en nuestro listado tanto las selecciones como las recopilaciones de cuentos que ya han aparecido publicados en libro y ahora aparecen extraídos de los mismos, pero no otros tipos de composi- 
ción como, por ejemplo, la publicación conjunta de dos volúmenes de relatos, ya publicados, de un autor, tal es el caso de El criador de gorilas. Un viaje terrible, del argentino Roberto Arlt o La tierra de muñecos. La tuna de oro, del venezolano Julio Garmendia. Otras veces, la recopilación, incluida en el apartado «obras», es realizada en vida del autor y recoge cuentos inéditos o dispersos en publicaciones periódicas, constituyendo así una publicación nueva, como ocurre con La vida difícil, del polaco Slawomir Mrozek. Este tipo de ordenación responde, entonces, a la simple reunión de relatos por mera yuxtaposición, como señala Gonzalo Sobejano (1992: 72), es decir, «se colocan los relatos, sin más, uno tras otro». La confusión extrema llega cuando, con los datos de que se dispone, es difícil distinguir con total seguridad si el volumen reseñado constituye una obra inédita o una antología, como puede suceder con El burdel de los gitanos, del rumano Mircea Eliade. Otras veces, ante la comprometida tesitura y ante la falta de argumentos claros, hemos resuelto el problema movidos por el instinto. Sirva de ejemplo la inclusión en el apartado de «Obras» de Los volátiles del Beato Angélico, de Antonio Tabucchi, traducción de un título homónimo en italiano del autor, de 1987, pero que incluye tres relatos de El juego del revés, publicado en 1986 por Anagrama. Creemos que aquí el criterio editorial ha estado por encima del carácter selectivo que se supone en una antología, de ahí nuestra elección.

2. Los límites del género es otro aspecto no suficientemente establecido, según se deduce al ojear las reseñas. Y así, aparecen numerosas formas de denominar al género, bien por la amplitud que éste encierra, bien por la difícil delimitación del mismo: dos formas de enfocar el mismo problema, pero ninguna lo resuelve.

La dificultad de aplicar un término que identifique el género puede venir motivada, en primer lugar, por las propias características del mismo, entre ellas la de la «extensión». Dicho concepto, en el sentido más simple de número de páginas o tiempo de lectura, no es el único rasgo que puede definir este tipo de textos, sino que hay que atender a otros de orden interno y que afectan a su estructura, a sus elementos narrativos o a su efecto sobre el lector, tales como la unidad de concepción y recepción, la unicidad e intensidad del efecto o la economía de recursos y técnicas (Pacheco, 1993: 13-27), entre otros. Una definición que intenta recoger la noción de «extensión» y la referencia a aspectos de carácter interno del cuento sería la de Seymour Menton (1993: 122), que dice: «El cuento es una narración, fingida en todo o en parte, creada por un autor, que se puede leer en menos de una hora y cuyos elementos contribuyen a producir un solo efecto».

En este sentido, tal definición podría ampliar los posibles límites del género en cuanto a las características internas del mismo y explicar por qué 
los críticos a veces consideran relatos o cuentos lo que en otro momento no se ha considerado como tal. Así, Joaquín Marco, en la crítica de Viaje a La Habana, de Reinaldo Arenas, a pesar de que el propio autor definió el libro como «novela», lo considera formado por tres relatos fechados en tres etapas distintas. José Méndez, al reseñar El final del cielo, de Alejandro Gándara, llama «cuento» a la historia de 175 páginas, que constituye el libro. J. Ernesto Ayala-Dip, al comentar El caballo de Balzac, de Gert Hofman, utiliza el término alemán «nouvellen», para nombrar los cuatro relatos que lo componen ${ }^{12}$. Por último, como compendio terminológico, aludimos a la crítica de Bajo los tilos, de la también alemana Christa Wolf, realizada por Miguel García-Posada, quien utiliza los conceptos de «novela corta», «novela», «narración» $y$ «relatos» para referirse a los tres textos incluidos en el volumen de 140 páginas.

Por otra parte - y quizá esto hable más de la riqueza del género que de su indeterminación o de su amplitud-, también se advierte, en un primer acercamiento a las reseñas encontradas, la diversa tipología textual que acoge o convive en un libro de relatos. Ya enumeraba Anderson Imbert (1979: 3743), al definir el cuento, las distintas formas cortas en que éste se puede presentar (artículo de costumbres, cuadro caracteriológico, noticia, mito, leyenda, ejemplos, anécdota, caso). Parecida variedad también la hemos podido encontrar nosotros. Así, se habla de «estampas» al comentar los cuentos incluidos en el volumen El gafe, de Paulino Masip; o en el de Gabriel Miró, titulado Años y leguas, referidas estas últimas a textos escritos en sus vacaciones veraniegas. Los textos incluidos en Los grandes relatos, de José Jiménez Lozano son considerados capítulos de un libro, rememoraciones de la niñez y juventud del autor. Días extraños, de Ray Loriga, además de ser considerado compuesto por relatos se define en la reseña como «un texto de difícil clasificación, un conjunto de textos que configuran una especie de diario intimo y muy personal».

Quizá lo indeterminado del género y su consideración de texto menor, es lo que lleve a juntar en algunos volúmenes, sobre todo los dedicados a recopilar la obra de los autores, textos que se alejan del género, creando un cajón de sastre lleno de muy distinto material. Así, hemos visto que algunos volúmenes reúnen, en el mejor de los casos, relatos y alguna novela corta o embrión de novela (El cálido verano del 44, de Jorge Ferrer-Vidal; Relatos granadinos, de Francisco Ayala; ¿Qué coños?, de Agustín García Calvo; Moriré esta primavera, de Roberto Velázquez Riera). Lo extremo llega

12 Según Gerard Gillespie (1993: 138), la terminología alemana de principios del siglo XIX, es la siguiente: Geschichte-Erzälung para las formas narrativas breves, Nouvelle para las formas intermedias y Roman para la extensas. 
cuando, en un mismo libro, se amalgaman artículos periodísticos, cuentos y declaraciones del escritor, como ocurre, por citar algún título, en Obra Breve I, de Arturo Pérez-Reverte.

3. Refiriéndonos ahora a otro motivo de reflexión a la hora de elaborar el listado, diremos que se han excluido del mismo las obras infantiles y juveniles, con la consiguiente necesidad de distinguir, de antemano, el cuento popular y tradicional —donde se incluyen también las colecciones del Barroco y del Romanticismo, como las de Charles Perrault y los Hermanos Grimm, hoy día adjudicadas al público más joven - y el cuento destinado originariamente a niños. El carácter anónimo, legendario y el interés antropológico de ciertos relatos nos han proporcionado motivos para incluirlos en la lista - por ejemplo, Cuentos y tradiciones japoneses, Caperucitas, cenicientas y marisabidillas, Catálogo Tipológico del cuento folklórico o Cuentos populares albaneses-, frente a los que, o bien el contenido de la reseña, o bien, y en último extremo, la consulta del ISBN, lo clasifican dentro del cuento infantil y juvenil.

4. Se puede deducir, a tenor de las reseñas recopiladas, que la publicación de cuentos, en general, y el cultivo del cuento en nuestra lengua, en particular, no pasa por un mal momento en nuestro país durante los años que ocupan este estudio. En relación con este aspecto, desde hace años vienen surgiendo opiniones de distinto signo sobre la poca o mucha atención que se presta al cuento, desde diversos ámbitos (autores, lectores, editoriales o crítica). Así, hemos anotado más de una veintena de referencias sobre opiniones en este sentido, aparecidas desde finales de los años 80 , las cuales se pueden dividir en dos bandos ${ }^{13}$. En el bando de los pesimistas - que ven falta de calidad en el cuento; poca atención de editores, escritores y medios de comunicación; o

13 La información existente, desde finales de los años 80, sobre este tema es amplia: MiLLÁs, Juan José (1988). «Lo que cuenta el cuento. El auge del relato breve». El País Domingo 107, 2122; NAVALES, Ana María (1988). «El auge invisible: Notas sobre el cuento español en la actualidad». República de las Letras 22, 63-66; PERAILE, Meliano (1988). República de las Letras 22, 67-70; FERRER-VIDAL, Jorge (1988). «Situación del cuento literario, en España». República de las Letras 22, 73-78; MARTínEZ-MENCHÉN, Antonio (1988). "Y va de cuento...". República de las Letras 22, 81-84; SORIANO, Elena (1988). República de las Letras 22, 91-96; ALPERI, Víctor (1988). «El cuento: Algunas reflexiones». República de las Letras 22, 99-102; BERLANGA, Andrés (1988). «Sobre el cuento». Ínsula 495, 24; Fralle, Medardo (1989). «¿El resurgir del cuento?». Ínsula 512-512, 10; MARÍAS, Javier (1990). «El cuento en España». Leer 30, 40; SATUE, Francisco J. (1990). «El cuento en España». Leer 30, 41; UMBRAL, Francisco (1990). «El cuento en España». Leer 30, 42; CEREZALES, Agustín (1990). «El cuento de la novela», $A B C$ 106, 7-1, 76; PerAlle, Meliano (1990). «El cuento, objeto de confusión». ABC 27.202, 7-1, 90, 64; SANZ VILlanueVA, Santos (1991). «El cuento de ayer y de hoy». Lucanor 6, 13-25; Acín, Ramón (1991). «El cuento y sus medios de difusión». Lucanor 6, 67-82; MARTín NOGales, José Luis (1991). «El cuento hoy en España». El Sol 65, 20-9; VALLS, Fernando (1993). «El Renacimiento del cuento en España (1975-1993). «En Son cuentos, Fernando Valls (ed.), 9-58. Madrid: Espasa-Calpe; EnCINAR, Ángeles y Anthony Percival (1993). «Contexto teórico-crítico, histórico y cultural». En Cuento español contemporáneo, Ángeles ENCINAR y Anthony PeRCIVAL (eds.), 11-44. Madrid: Cátedra; Sanz Villanueva, Santos (1993). «En la hora presente del 
escaso éxito de lectores y de publicaciones- se hallan narradores como Andrés Berlanga, Javier Marías, Meliano Peraile, Agustín Cerezales, Luis Mateo Díez, Ana María Navales, Jorge Ferrer-Vidal, Antonio MartínezMenchén y Fernando Quiñones. El grupo de los más optimistas —que argumentan, por el contrario, razones tales como la influencia del género en la literatura actual, su mayor presencia en la prensa, una actitud más abierta de editoriales y escritores, la aparición de nuevos autores- lo forman creadores como Juan José Millás, Medardo Fraile o Elena Soriano y críticos como Santos Sanz Villanueva, Ramón Acín, José Luis Martín Nogales, Fernando Valls o Ángeles Encinar. La última reflexión recogida sobre este tema la constituye el artículo de Antonio del Rey (1999), «Claves del cuento actual», publicado en el n. 16 de la revista Lucanor. En él dice, entre otras cosas, que «esta suerte de victimismo generalizado que se ha propagado entre - principalmente- los autores (mejor dicho, determinados autores) de cuentos no tiene demasiado fundamento» (1999: 90). Más bien al contrario, Antonio del Rey (1999: 93) considera que existe un florecimiento del género, tal como confirman los datos y él argumenta en su referido artículo.

Si en algo contribuye a esta idea, en lo relativo al cuento español, podemos hacer un breve análisis comparativo con el número de libros editados desde 1975 hasta 1995. Para ello, unimos nuestra información a la aportada por el repertorio bibliográfico publicado por Fernando Valls y Nuria Carrillo (1991) en el n. 6 de Lucanor, bajo el título «El cuento español actual. Cronología» y observamos un sostenido crecimiento de títulos en los primeros cinco años de los 90 , hecho que tal vez pueda ser corroborado tras consultar el listado, también confeccionado para este Seminario, de Dolores Romero y Francisco Linares sobre los años 1996 a 1999, e igualmente sobre los mismos suplementos utilizados aquí.

Así, el número de libros de cuentos publicados, durante estos veinte años que manejamos, es el siguiente:

\begin{tabular}{|c|c|c|c|}
\hline Año & $75 \quad 76 \quad 77787980 \quad 8182$ & 283848586 & 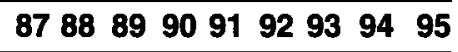 \\
\hline ros & 11 & 2 & 31 \\
\hline
\end{tabular}

Observamos, pues, que es a partir, precisamente, de 1989 cuando el número de cuentos publicados supera la treintena, hecho que se mantendrá en 1990, 1991, 1993 y 1994.

cuento". En Últimos narradores. Antología de la reciente narrativa breve española, Joseluis González y Pedro DE Miguel (eds.), 7-10. Pamplona: Hierbaola; EnCINAR, Ángeles (1995). «Tendencias en el cuento español reciente». Lucanor 13, 103-118; VALLS, Fernando (1998. «La continuidad del cuento: entre la disciplina y la libertad». En Los cuentos que cuentan. J. A. MASOLIVER RÓDENAS y Fernando VALLS, (eds.), 11-17. Barcelona: Anagrama. 
Dicha tendencia ascendente queda plasmada gráficamente de la siguiente forma:

\section{EVOLUCIÓN DE LA PUBLICACIÓN DE LIBROS CUENTOS ESPAÑOLES (1975-1995)}

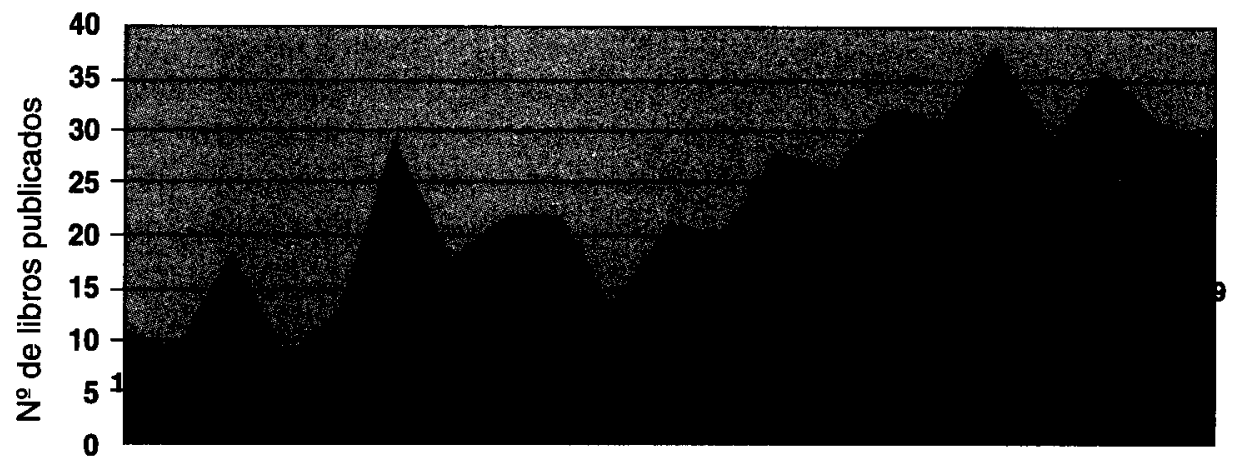

De 1975 a 1995

Otra información que sirve para valorar la situación del cuento en los 90 , en un sentido general, es la que se extrae de observar la cantidad de cuentos publicados en los periódicos durante los años que nos ocupan, si bien tal cometido excede al que presentamos en estas páginas. No obstante, y a modo de orientación, podemos señalar que durante los años que hemos manejado se han publicado, en el $A B C$ y en $E l$ País, casi 300 cuentos o relatos, que se unen a los más de 450 aparecidos en los cinco años anteriores. El País concentra dichas publicaciones en épocas de vacaciones veraniegas, bajo el letrero de «Relato de verano» (1992 y 1993), «Verano 94» (1994), «Intrigas de verano» (1995), «Relatos de seducción» (1995), o se aprovecha el tema navideño, como en «Cinco cuentos de Navidad» (1992) o «Cuatro cuentos de Navidad» (1995). $A B C$ lanza, entre febrero de 1993 y diciembre de 1994, un suplemento, de periodicidad mensual, titulado «Periolibros», donde aparecen textos de autores ya consagrados, la mayoría de ellos relatos.

Un tercer argumento, referido a la vitalidad del cuento español, estaría en relación con las veintiuna antologías recogidas ${ }^{14}$, en las que se seleccionan cuentos de diversos autores españoles. Sin olvidar el inevitable oportunismo que encierran algunas de estas publicaciones, podemos obtener con ellas una visión panorámica de la situación.

14 Con el fin de agilizar la exposición, y al igual que con otros citados anteriormente, omitimos aquí los datos bibliográficos de dichas antologías, los cuales se pueden consultar en el anexo citado al principio. 
Algunas de estas antologías son fruto de la recopilación de textos destinados con anterioridad al medio periodístico — Relatos urbanos (1994); Cuentos de la isla del tesoro (1994)—. Otras, utilizan el criterio temático y dan cuenta de la diversidad a este respecto - Los pecados capitales (1990); Relatos eróticos (1990); Negro como la noche (1991), de tema policíaco; Antología española de la literatura fantástica (1992); Cuentos de fútbol (1995)-. Otras, agrupan los relatos en función de criterios temporales - unidos, en algunos casos también, a una ordenación temática-o espaciales - Cuentos modernistas (1994); Antología de la novela corta erótica española de entreguerras (1993); De la Luna a Mecanópolis. Antología de la ciencia-ficción española (1832-1913) (1995); Retablo y geografía de cuentos canarios (1993)—. Pero, sin duda, las más valiosas, en tanto que aportan una amplia muestra de autores y tendencias actuales, así como un estudio o prólogo introductor que resume el panorama, son las siguientes: Últimos narradores (1993), de Hierbaola; Cuento español contemporáneo (1993), de Cátedra; y Son cuentos (1993), de Espasa-Calpe.

Seguimos insistiendo sobre el interés del cuento español en los 90 y lo hacemos ahora desde el lado de los escritores. Así, de los 124 autores de relatos —descartando, claro está, las antologías y los textos anónimos- de los que dan cuenta las reseñas, diez han nacido en el siglo XIX (Max Aub, Azorín, Clarín, Manuel Chaves Nogales, Antonio Espina, Gabriel Miró, José Moreno Villa, Pereda, Valle-Inclán y Mario Verdaguer). Los demás, ya del siglo XX, se hallan repartidos en las distintas etapas o generaciones establecidas por los estudiosos ${ }^{15}$ de la siguiente forma:

— Nacidos entre 1900 y 1915 (Generación del 36): 7.

- Nacidos entre 1916 y 1930 (Generación de los 50 o del medio siglo): 27.

- Nacidos entre 1931 y 1945 (Generación del 68): 19.

- Nacidos a partir de 1946 (Última generación): 61.

Se observa una amplia ventaja de los autores de la última generación, que nosotros hemos alargado hasta la actualidad y en la que ya se incluyen escritores nacidos en los años 60 , los cuales constituyen un vivificador relevo para el género (Juan Bonilla, Marcos Giralt Torrente, Ray Loriga, Luis Magrinyá, Daniel Múgica, Juan Manuel de Prada, Care Santos, Eloy Tizón o Pedro Ugarte, entre otros).

15 Para corroborar dichas diferenciaciones generacionales en el cuento -extensible también al cultivo de otros géneros, durante el siglo XX - citamos, a modo de ejemplo, las siguientes fuentes: FraILE, Medardo (1988). «Introducción». En Cuento español de Posguerra, Medardo FraILE, (ed.), 11-38. Madrid: Cátedra; JIMÉNEZ MADRID, Ramón (1991). «Tres generaciones frente al cuento». Lucanor 6, 55-66; MARTín Nogales, José Luis (1994). «El cuento español actual. Autores y tendencias». Lucanor 11, 43-65. 
Un último dato para defender el buen momento del cuento en la primera mitad de los 90 lo aporta el sector editorial. Ya Ángeles Encinar (1995: 103), al hablar del «cierto apogeo» del cuento en 1994, nombra las editoriales Alfaguara, Anagrama, Destino y Tusquets como aquéllas que, entre otras, han dado cabida al género. Son muchas más las que muestran su interés por publicar colecciones de relatos, tal y como queda demostrado en las siguientes relaciones y gráficos y como también constata Fernando Valls (1998: 12), incluyendo a otras más modestas como Pre-Textos, Aguaclara, Valdemar y Lengua de Trapo:

\begin{tabular}{|c|c|c|c|}
\hline \multicolumn{4}{|c|}{ Editoriales que publican libros de cuentos españoles en español } \\
\hline Editorial & N.9 de libros & Editorial & V.9 de libros \\
\hline Alfaguara & 13 & Anagrama & 8 \\
\hline Libertarias & 11 & Tusquets & 6 \\
\hline Edhasa & 9 & Pre-Textos & 4 \\
\hline Espasa-Calpe & 9 & Planeta & 4 \\
\hline Mondadori & 9 & Otros (con 3 o menos títulos publicados) & 97 \\
\hline Destino & 9 & & \\
\hline \multicolumn{4}{|c|}{$\begin{array}{l}\text { Editoriales que publican libros de cuentos hispanoamericanos, } \\
\text { extranjeros o en otras lenguas del país }\end{array}$} \\
\hline Editorial & N.9 de libros & Editorial & V.? de libros \\
\hline Anagrama & 19 & Tusquets & 5 \\
\hline Siruela & 15 & Mondadori & 5 \\
\hline Alfaguara & 13 & Versal & 5 \\
\hline Seix-Barral & 9 & Ediciones B & 5 \\
\hline Edhasa & 8 & Anaya \& Mario Munick & 4 \\
\hline Destino & 8 & Circe & 4 \\
\hline Alianza & 7 & Otros (con 3 o menos títulos publicados) & 65 \\
\hline Cátedra & 7 & & \\
\hline
\end{tabular}

Observamos que la dispersión editorial es mayor a la hora de publicar volúmenes de cuentos españoles en castellano (76 editoriales para 179 libros) que al editar volúmenes de relatos hispanoamericanos, extranjeros o 
de las demás lenguas del país (56 editoriales para 179 títulos). Tal evidencia supone, por un lado, el mayor riesgo que se asume con el relato local, muchas veces publicados por editoriales pequeñas o por instituciones públicas $\mathrm{y}$, por otro, el carácter minoritario, en cuanto a lectores, del género, el cual no parece suponer un producto prioritario para las grandes editoriales. Además, estas grandes editoriales, en la mayoría de los casos, - véase Alfaguara, Alianza, Anagrama, Anaya \& M. Munick, Cátedra, Debate, Destino, Ediciones B, Península, Siruela, Seix-Barral, Sirmio o Versal- publican mayor número de títulos extranjeros que nacionales en un total que se reparte, exactamente, al 50\%. De todo lo anteriormente expuesto, se deduce el auge del cuento en España en el periodo estudiado

\section{Referencias bibliográficas 16}

Acín, Ramón (1990). Narrativa o consumo literario (1975-1987). Zaragoza: Prensas Universitarias de Zaragoza.

CARRILlo, Nuria (1997). El cuento literario español en la década de los 80. Madrid: FIDESCU.

ENCINAR, Ángeles (1995). «Tendencias en el cuento español reciente». Lucanor 13, 103-118.

GILLESPIE, Gerard (1993). «¿Novela, Nouvelle, Novela [corta], Short novel: Una revisión de términos». En Del cuento y sus alrededores, Carlos Pacheco y Luis Barrera Linares (eds.), 131-146. Caracas: Monte Ávila Latinoamericana.

IMBERT, Anderson (1979). Teoría y técnica del cuento. Buenos Aires: Marimar Ediciones. Menton, Seymour (1993). «Sobre el cuento hispanoamericano». En Del cuento y sus alrededores, Carlos Pacheco y Luis Barrera Linares (eds.), 121-122. Caracas: Monte Ávila Latinoamericana.

PACHECO, Carlos (1993). «Criterios para una conceptualización del cuento». En Del cuento y sus alrededores, Carlos Pacheco y Luis Barrera Linares (eds.), 13-28. Caracas: Monte Ávila Latinoamericana.

REY, Antonio del (1999). «Claves del cuento actual». Lucanor 6, 89-113.

SoBEjano, Gonzalo (1992). «Sobre los criterios de ordenación de un libro de cuentos».

En Papeles sobre el cuento español contemporáneo, Joseluis González (ed.), 7175. Pamplona: Hierbaola.

Valls, Fernando y Nuria Carrillo (1991). «El cuento español actual. Cronología». Lucanor 6, 83-92.

VALLS, Fernando (1998). «La continuidad del cuento: Entre la disciplina y la libertad». En Los cuentos que cuentan, J. A. Masoliver Ródenas y Fernando Valls (eds.), 1117. Barcelona: Anagrama.

16 Remitimos a las referencias bibliográficas expresadas en las notas anteriores de este trabajo que, por problemas de espacio, no incluimos aquí. 